\title{
Subthalamic Nucleus Neurons Are Synchronized to Primary Motor Cortex Local Field Potentials in Parkinson's Disease
}

\author{
Shoichi A. Shimamoto, ${ }^{1 \star}$ Elena S. Ryapolova-Webb, ${ }^{1 \star}$ Jill L. Ostrem, ${ }^{2}$ Nicholas B. Galifianakis, ${ }^{2,3}$ Kai J. Miller, ${ }^{4}$ \\ and Philip A. Starr ${ }^{1,3}$ \\ Departments of ${ }^{1}$ Neurological Surgery and ${ }^{2}$ Neurology, University of California, San Francisco, California 94143, and 3Parkinson's Disease Research, \\ Education, and Care Center, San Francisco Veteran's Affairs Medical Center, San Francisco, California 94143-0114, and ${ }^{4}$ Department of Neurosurgery, \\ Stanford University, Stanford, California 94305
}

In Parkinson's disease (PD), striatal dopamine denervation results in a cascade of abnormalities in the single-unit activity of downstream basal ganglia nuclei that include increased firing rate, altered firing patterns, and increased oscillatory activity. However, the effects of these abnormalities on cortical function are poorly understood. Here, in humans undergoing deep brain stimulator implantation surgery, we use the novel technique of subdural electrocorticography in combination with subthalamic nucleus (STN) single-unit recording to study basal ganglia-cortex interactions at the millisecond time scale. We show that in patients with PD, STN spiking is synchronized with primary motor cortex (M1) local field potentials in two distinct patterns: first, STN spikes are phase-synchronized with M1 rhythms in the theta, alpha, or beta $(4-30 \mathrm{~Hz})$ bands. Second, STN spikes are synchronized with M1 gamma activity over a broad spectral range $(50-200 \mathrm{~Hz})$. The amplitude of STN spike-synchronized gamma activity in M1 is itself rhythmically modulated by the phase of a lower-frequency rhythm (phase-amplitude coupling), such that "waves" of phase-synchronized gamma activity precede the occurrence of STN spikes. We show the disease specificity of these phenomena in PD, by comparison with STN-M1 paired recordings performed in agroup of patients with a different disorder, primary craniocervical dystonia. Our findings support a model of the basal ganglia-thalamocortical loop in PD in which gamma activity in primary motor cortex, modulated by the phase of low-frequency rhythms, drives STN unit discharge.

\section{Introduction}

Much work has been done to define the electrophysiology of the basal ganglia nuclei in humans with movement disorders. In Parkinson's disease (PD) patients off dopaminergic medications, subthalamic nucleus (STN) neurons have increased neuronal firing rates (Hutchison et al., 1998; Steigerwald et al., 2008; Schrock et al., 2009), oscillatory firing patterns in the theta $(4-8 \mathrm{~Hz})$, alpha $(8-12 \mathrm{~Hz})$, and beta $(12-30 \mathrm{~Hz})$ ranges (Rodriguez-Oroz et al., 2001; Levy et al., 2002b), and exaggerated synchronization to neighboring STN units and to STN local field potentials (LFPs) in the beta range (Levy et al., 2002b; Kuhn et al., 2005; Weinberger et al., 2006; Moran et al., 2008). Excessive basal ganglia neuronal spike synchronization is also well established in animal models of parkinsonism (Nini et al., 1995; Goldberg et al., 2004; Costa et al., 2006).

\footnotetext{
Received Oct. 1, 2012; revised March 1, 2013; accepted March 14, 2013.

Author contributions: S.A.S. and P.A.S. designed research;S.A.S., E.S.R.-W., J.L.O., N.B.G., and P.A.S. performed research; J.L.O. and N.B.G. contributed unpublished reagents/analytic tools; S.A.S., E.S.R.-W., K.J.M., and P.A.S. analyzed data; S.A.S. and P.A.S. wrote the paper.

This work was supported by the National Institutes of Health (Grant R01NS069779 to P.A.S.), and the Dystonia Medical Research Foundation. We thank Leslie Markun and Marta San Luciano for assistance with clinical data and statistical analyses, and Coralie de Hemptinne for critical review of the paper.

*S.A.S. and E.S.R.-W. contributed equally to this work.

The authors declare no competing financial interests.

Correspondence should be addressed to Dr. Philip Starr, Department of Neurological Surgery, University of Cali-

fornia, 779 Moffitt, 505 Parnassus Avenue, San Francisco, CA 94143. E-mail: starrp@neurosurg.ucsf.edu.

S. Shimamoto's present address: Tulane University School of Medicine, New Orleans, LA 70112

DOI:10.1523/JNEUROSCI.4676-12.2013

Copyright $\odot 2013$ the authors $\quad 0270-6474 / 13 / 337220-14 \$ 15.00 / 0$
}

The role of the motor cortex in parkinsonian pathophysiology is less clear. Scalp electroencephalography and invasive LFP studies in humans without movement disorders show that beta frequency oscillations are normally present in motor cortex (Pfurtscheller et al., 1997; Crone et al., 1998; Miller et al., 2007). In rodent models, cortical beta rhythms are excessively synchronized to basal ganglia spike discharge (Mallet et al., 2008; Brazhnik et al., 2012), but it is not known whether this is true in humans with PD. Further, interactions between basal ganglia spiking and higher frequency cortical activity have not been explored. The broad range of gamma frequencies between 50 and $200 \mathrm{~Hz}$, often referred to as "broadband gamma" (Ossandon et al., 2011), is probably a surrogate measure of underlying asynchronous spiking (Manning et al., 2009), and task-related changes in broadband gamma are thought to reflect localized cortical function (Lachaux et al., 2012). Further, broadband gamma activity in primary motor cortex is elevated in PD (Crowell et al., 2012), as well as excessively coupled to the phase of low-frequency cortical rhythms (phase-amplitude coupling) (de Hemptinne et al., 2013). Thus, analysis of the interaction of basal ganglia spiking with cortical broadband could yield great insight into basal ganglia-cortex dynamics in PD.

To address these questions, we recorded primary motor cortex (M1) arm area LFPs simultaneously with STN unit discharge, in awake patients undergoing deep brain stimulator (DBS) implantation surgery. M1 LFPs were recorded using subdural electrocorticography (ECoG), a technique that combines excellent spatial and temporal resolution with sufficient signal amplitude 
to resolve high-frequency broadband activity, in addition to lowfrequency rhythms, relatively free of artifact. To provide a comparison group, we performed similar recordings in patients with primary craniocervical dystonia who had minimal symptoms in the contralateral arm. We tested the hypothesis that in PD, STN single-unit discharge at rest is excessively synchronized to cortical oscillations, to cortical broadband gamma activity, and to epochs of cortical phase-amplitude coupling. Our findings support a model of the basal ganglia-thalamocortical loop in PD in which cortical $4-30 \mathrm{~Hz}$ rhythms are phase-locked to gamma activity, and in which phase modulated "waves" of gamma activity in motor cortex drive STN hyperactivity.

\section{Materials and Methods}

Subject recruitment and clinical characterization. Study subjects were recruited from a population of movement disorders patients scheduled to undergo DBS implantation at one of two campuses: the University of California at San Francisco (UCSF), or the San Francisco Veterans Affairs Medical Center (SFVAMC). Subjects had a diagnosis of idiopathic PD, or primary cervical or craniocervical dystonia, confirmed by a movement disorders neurologist (J.L.O. or N.B.G.). The dystonia patients included in this study were simultaneously participating in a clinical trial to evaluate the effectiveness of STN DBS in dystonia (Ostrem et al., 2011). Informed consent was obtained before surgery under a protocol approved by the UCSF/SFVAMC Institutional Review Board, according to the Declaration of Helsinki. During the consent process, it was explained to each prospective subject that the temporary intraoperative placement of the cortical recording strip was performed solely for research purposes. Potential study subjects were characterized within $60 \mathrm{~d}$ before surgery using the following standardized rating scales: for PD patients, the Unified Parkinson's Disease Rating Scale part III (UPDRS-III) after withdrawal of anti-parkinsonian medications for $12 \mathrm{~h}$; for dystonia patients, the Burke-Fahn-Marsden dystonia rating scale (BFMDRS) movement score, and the Toronto Western Spasmodic Torticollis Rating Scale (TWSTRS) severity score. For PD patients, preoperative UPDRS-III subscores for the hemibody contralateral to brain recordings were used in some analyses for correlations with physiological data. However, tremor was also scored for each individual recording as "present" or "absent" intraoperatively based on off-line visual inspection of limb electromyography (EMG) and accelerometry (detailed further below). Preoperative medications in PD were summarized as levodopa-equivalent doses (LED) using the following conversion factors: ropinirole $\times 20$; pramipexole $\times 100$; levodopa with decarboxylase inhibitor $\times 1$; controlled release levodopa with decarboxylase inhibitor $\times 0.7$; levodopa with decarboxylase and COMT inhibitor $\times 1.3$ (Wenzelburger et al., 2002).

Subject inclusion criteria were as follows: age 21-75 years, normal brain magnetic resonance imaging (MRI) examination, sufficient disease severity in the setting of optimal medical management to justify treatment by DBS, and ability to cooperate during awake neurosurgery. Further criteria for the primary dystonia group: dystonia affecting predominantly cervical or craniocervical muscles with minimal arm involvement, and no treatment with injected Botulinum toxin for 3 months before surgery. Twenty-nine PD patients and six dystonia patients met study criteria and were included.

Placement of subdural ECoG electrodes and STN microelectrodes. All subjects underwent typical procedures for planning and stereotactic surgical placement of deep brain stimulator electrodes into the STN (Starr et al., 2002). On the surgical planning MRI, the STN target was identified as a signal hypointensity on T2-weighted fast spin-echo imaging lateral to the anterior border of the red nucleus, typically 11-13 mm from the midline. For targeting M1 for placement of the ECoG array, we identified a point on $\mathrm{M} 1,3 \mathrm{~cm}$ from the midline, based on anatomic identification of the central sulcus (Fig. 1A). The intention was to target the arm-related area of M1, slightly medial to the "hand knob" (Yousry et al., 1997), in the same parasagittal plane as the typical surgical entry site for placement of STN DBS electrodes. A radio-opaque marker was stereotactically placed on the scalp over this location. When bilateral DBS implantations were planned, cortical recording was performed on one side only, typically the side with the clearest anatomic demarcation of the central sulcus. After drilling of frontal burr holes, and opening of the dura mater, we placed a six-contact subdural ECoG strip ( $3 \mathrm{~mm}$ contacts, $1 \mathrm{~cm}$ spacing) (AdTech or Integra) on the brain surface and directed it posteriorly in a parasagittal plane under fluoroscopic control to provide contacts covering both M1 and primary sensory cortex (S1). The locations of the burr holes were determined solely by the selection of the safest entry point for the intended DBS trajectory, and no additional skull or scalp exposure was needed for ECoG strip placement. After placement of the ECoG strip and guide tube for microelectrode recording, the burr hole was sealed with a fibrin sealant.

Confirmation of ECoG electrode location. ECoG contact locations were confirmed anatomically using intraoperative CT (iCT) (O-arm, Medtronic) (Shahlaie et al., 2011) or lateral fluoroscopy. iCT images were computationally fused to the preoperative planning MRI using standard surgical planning software (Framelink 5.1, Medtronic), and windowed so as to visualize each ECoG contact with respect to underlying MRI anatomy (Fig. $1 B$ ). For cases where lateral fluoroscopy only was used, a lateral x-ray documented the location of the ECoG contact in the anteriorposterior direction with respect to the radio-opaque scalp marker.

For physiological confirmation of electrode location, we recorded somatosensory evoked potentials (SSEPs) generated by median nerve stimulation. The stimulation parameters were as follows: pulse frequency, 2 $\mathrm{Hz}$; pulse width, $200 \mu \mathrm{s}$; pulse train length, 160; current 25-35 mAmp (typically $50 \%$ higher than the threshold for visible thumb twitch). Signals recorded from the ECoG strip during the SSEP were sampled at 5000 $\mathrm{Hz}$, bandpass filtered $(1-500 \mathrm{~Hz})$, and amplified $\times 7000$. Signal averaged SSEPs for each adjacent contact pair (computationally re-montaged) were then visually inspected to determine the M1 location by reversal of the N20 waveform. For each bipolar pair, the more posterior contact was used as the "active" electrode, whereas the more anterior was the "reference". The posterior contact of the most posterior bipolar contact pair that showed a negative going waveform was considered to be the contact best localized to M1 (Fig. 1C). There was high concordance between anatomic and physiologic determinations of contact position with respect to the central sulcus.

Cortical LFP and STN single-unit recording. Cortical LFPs and STN units were recorded in a state of alert rest, using the Guideline 4000 system (FHC) or the Alpha Omega Microguide Pro (Alpha Omega). These are customized 14-channel data collection systems approved by the United States Food and Drug Administration for human use. Fivechannel cortical LFP recordings were obtained from each of the five most posterior ECoG contacts ( $\mathrm{C} 1-\mathrm{C} 5)$, each differentially referenced to the most anterior contact (C6). A needle electrode in the scalp served as the ground. LFP signals were bandpass filtered $1-500 \mathrm{~Hz}$, amplified $\times 7000$, and sampled at $1000 \mathrm{~Hz}$ (Guideline 4000 system) or $1500-3000 \mathrm{~Hz}$ (Alpha Omega). A $60 \mathrm{~Hz}$ notch filter was used to reduce line artifact. Data collected with the Alpha Omega system were downsampled to $1000 \mathrm{~Hz}$ (MATLAB function resample). All subjects had been sedated with propofol for the initial surgical exposure, but data collection was performed at least $30 \mathrm{~min}$ after stopping propofol. This is sufficient time for all neuronal effects of this agent to be eliminated (Fechner et al., 2004; Raz et al., 2008). Simultaneous EMG (biceps brachii, extensor carpi radialis, and gastrocnemius) and arm accelerometry were performed to confirm the absence of voluntary movement, and presence or absence of tremor, during recording. All raw, unfiltered EMG and accelerometry recordings were visually inspected off-line, and if $4-6 \mathrm{~Hz}$ oscillations were present in at least one EMG or accelerometry trace for a minimum continuous duration of $10 \mathrm{~s}$, the corresponding single-unit/M1 LFP recording was scored as "tremor present"; otherwise it was scored as "tremor absent". When present, 4-6 Hz oscillations typically were seen during most or all of the recording, and scoring was based on concurrence between two examiners. Because tremor can occur transiently, some recordings from a single subject could be scored as tremor present, whereas others were tremor absent.

STN neuronal recordings were obtained using glass-coated platinum/ iridium microelectrodes with impedance $0.4-1.0 \mathrm{M} \Omega$ at $1000 \mathrm{~Hz}$ (FHC or Alpha Omega) as previously described (Starr et al., 2002). Microelec- 

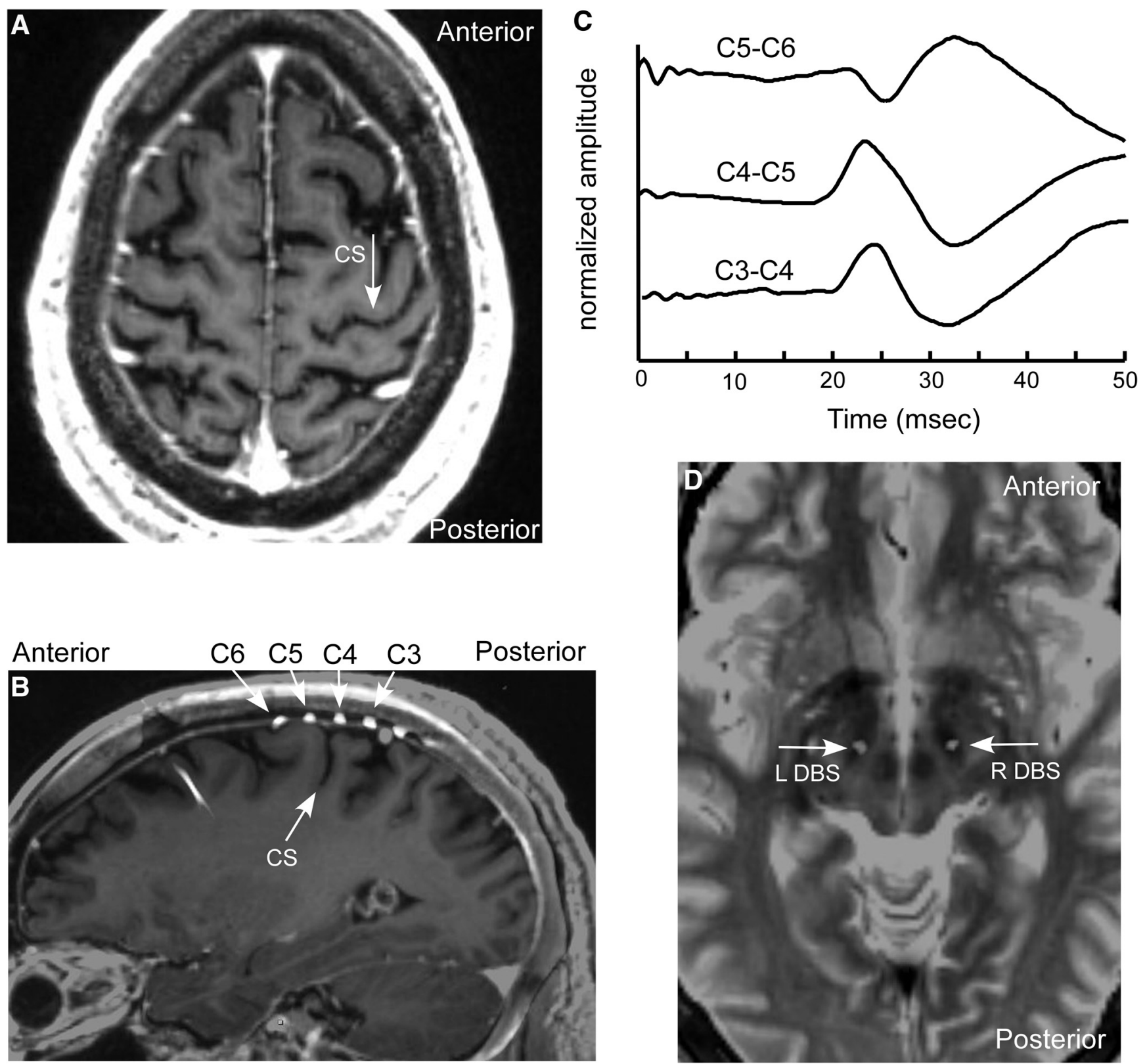

Figure 1. Method of localization of ECOG electrode contacts and of STN recording site. $A$, Intended location (white arrow) of the center of the ECOG recording strip, immediately anterior to the central sulcus (CS), on preoperative T1-weighted planning MRI, axial view. $\boldsymbol{B}$, Actual location of the recording contacts on the ECoG strip, from intraoperative $\mathrm{CT}$ computationally fused with the preoperative planning MRI, on parasagittal view $3 \mathrm{~cm}$ from the midline. 5 is the contact best localized to M1 by MRl in this example. C, Somatosensory evoked potential (from stimulation of the median nerve) for three adjacent contact pairs. Reversal of the N20 potential at contact pairs more posterior than 5 - 66 confirms 5 as the contact best localized to M1. D, Location of the STN DBS electrodes. The intraoperative (T, showing the lead artifacts (white arrows), is computationally fused with the preoperative axial T2-weighted MRI, which shows the STN as a region of T2 hypointensity.

trodes were advanced into the brain using a motorized or manual microdrive (Alpha Omega or Elekta). In a typical surgical case, 1-2 microelectrode penetrations were made serially through the STN on each side, separated by $2-3 \mathrm{~mm}$. Signals were bandpass filtered $(300 \mathrm{~Hz}$ to 3 $\mathrm{kHz}$ ), amplified, played on an audio monitor, displayed on an oscilloscope, and digitized (20 kHz sampling rate). Cells were recorded at approximately every $300-800 \mu \mathrm{m}$ along each trajectory, and each recording lasted $30-120 \mathrm{~s}$. Neurons were screened for movement-related activity based on audible changes in action potential discharge evoked by passive (investigator-initiated) contralateral limb movements (i.e., shoulder, elbow, wrist, hip, knee, and ankle joints). Proprioceptive responsiveness of a neuron in relation to movements of one or more joints was determined by concurrence between the examiner, and one or more operating room staff based on audiovisual assessments of the response. Only neurons recorded in the dorsal $4 \mathrm{~mm}$ of the nucleus, in a region where movement related activity was detected, and in which a minimum of 1000 spikes were digitized, were used for subsequent analysis.

Confirmation of STN localization. Most STN units (89\%) were recorded on the same trajectory as the final DBS electrode placement. Postoperative MRI, or CT computationally fused to the preoperative MRI (Framelink 5.1 software, Medtronic) (Fig. 1D), was performed to verify appropriate localization of the DBS electrode in the STN.

Single-unit discharge properties. Digitized spike trains were imported into off-line spike-sorting software (Plexon) for discrimination of single populations of action potentials by principal components analysis (Adamos et al., 2008). The software generated a record of spike times (subsequently reduced to millisecond accuracy) for each action potential waveform detected. The first 1000 spike times were used to calculate discharge rate and oscillatory activity in the $0-200 \mathrm{~Hz}$ range. Analyses were performed using MATLAB software (MathWorks). Neuronal data 
were accepted as single-unit data in this study only if action potentials could be discriminated with a high degree of certainty, as indicated by the presence of a clear refractory period of at least $3 \mathrm{~ms}$ in the interspike interval (ISI) histogram. Neurons whose action potential morphology varied greatly in synchrony with the cardiac cycle were excluded. Oscillations in the spike train at $0-50 \mathrm{~Hz}$ were evaluated using the "global spike shuffling" method (Rivlin-Etzion et al., 2006) to eliminate the artifactual autocorrelations that arise from the neuronal refractory period. Spike time stamps were converted to a data stream consisting of $1 \mathrm{~ms}$ bins in which the occurrence or absence of a spike was represented by 1 or 0 , respectively, in that bin. A 2048-point fast Fourier transform with Hanning window was used, resulting in a spectral resolution of $0.5 \mathrm{~Hz}$. Similar analysis was performed on "control" data in which ISIs had been randomly shuffled 100 times (Rivlin-Etzion et al., 2006). Statistically significant peaks in the spike train data (after normalization with the spectrum of the shuffled data) were determined by using the $300-500 \mathrm{~Hz}$ part of the spectrum as the control segment and its SD was used as a measure of random fluctuations in the spectrum. Each frequency point between 0.25 and $200 \mathrm{~Hz}$ was then checked for deviation from the expected power, at a significance level of $p=0.0025$, after correction for multiple (100) comparisons. Only $4-50 \mathrm{~Hz}$ oscillations were plotted as few occurred outside of this range.

LFP power spectra. For analysis of cortical LFPs, the raw strip recordings were computationally re-referenced to adjacent bipolar pairs by subtraction of the common reference. The M1 contact was referenced to either the contact immediately anterior or the contact immediately posterior to it, depending on which pair showed a larger spike-timed average waveform (described further below). The M1 LFP power spectrum was calculated using the Welch method (MATLAB function pwelch) with a 512-point FFT, for $1.96 \mathrm{~Hz}$ resolution, using the entire LFP recording (duration of recordings 34.3-140.0 s).

Data analysis: STN spike synchronization to M1 LFP oscillations. The first 1000 consecutive spike times of each recording were used for all analyses of spike-cortex synchronization. To provide a sensitive measure of spike-LFP interactions and to calculate latencies between the timing of spikes and peaks in cortical oscillatory activity, we analyzed the spiketimed average (STA) of the M1 LFP. The STA was computed in a $1 \mathrm{~s}$ window centered on the time of occurrence of STN spikes. We used the STA to calculate an STN spike-M1 LFP oscillation modulation index $\mathrm{MI}_{\mathrm{O}}$ as follows (see Fig. 3B-D). (1) The peak frequency of the STA was determined from the maximum of its power spectrum (512-point FFT, MATLAB function pwelch, $1.96 \mathrm{~Hz}$ resolution) (see Fig. $3 B$, inset). (2) We bandpass filtered the STA with a frequency band of width $4 \mathrm{~Hz}$, centered on the peak frequency [100 tap FIR filter implemented using MATLAB function filtfilt for bidirectional filtering to avoid filterinduced phase shifts (Moran et al., 2008)]. (3) We calculated the amplitude envelope of the bandpass-filtered STA time series as the magnitude of its (complex valued) analytic signal (see Fig. $3 C$ ). The analytic signal was generated from the sum of the bandpass-filtered STA and its Hilbert transform (MATLAB function hilbert). (4) We restricted the analysis to a $400 \mathrm{~ms}$ window centered on time 0 . The maximum value of the STA amplitude envelope was determined, and a mean value (Mtest) was computed using a $100 \mathrm{~ms}$ window around the peak-this was considered to be a "raw" measure of spike-M1 rhythm synchronization. For the same time period, a surrogate mean amplitude envelope (Mrev) and its SD (SDrev) were computed from the same cortical LFP data, but using temporally reversed spike times (see Fig. 3D). Mrev and SDrev were computed from a single time-reversed dataset (400 samples over a $400 \mathrm{~ms}$ window) providing a simple measure of STA fluctuations in the absence of synchronization. We defined the STN spike-M1 oscillation modulation index $\mathrm{MI}_{\mathrm{O}}$ as (Mtest - Mrev)/SDrev, thus generating a $z$-scored index of the magnitude of synchronization between simultaneously recorded STN spikes and M1 LFPs. (5) Some STAs contained two frequency components, as indicated by two peaks in their power spectra; in these cases, an $\mathrm{MI}_{\mathrm{O}}$ was also defined for the secondary frequency.

$\mathrm{MI}_{\mathrm{O}}$ values $>3$ were considered to be statistically significant. This threshold resulted in the occurrence of false-positives (recordings in which the reverse time STA analytic amplitude Mrev also crossed the 3.0 SD level at some time within the $400 \mathrm{~ms}$ STA test window) at a frequency of $<5 \%$. For all STAs that exceeded the threshold of significance, we tabulated: (1) the frequency of peak spectral power, calculated as described in step 1 above (see Fig. 3B); (2) the instantaneous phase value of the bandpass-filtered STA at spike time (time 0) (see Fig. 3C); (3) the latency from time 0 to the time of the peak of the amplitude envelope of the bandpass-filtered STA (see Fig. 3C); and (4) the duration of the interval over which the amplitude envelope of the STA crossed and stayed above the threshold of 3 SDs (see Fig. 3D). Of note, the exact time at which an STA amplitude envelope crosses its significance threshold is in part related to the frequency of the underlying oscillation, not just the strength of the STN-M1 interaction. Therefore, analyses of latency and duration of spike-LFP synchronization were only used as general descriptors, not for detailed comparison between subject groups.

To confirm the overall frequency characteristics of spike-M1 synchronization obtained by analyses of STN spike-timed averages of the M1 LFP, we also calculated STN spike-cortical LFP coherence using traditional methods for determining coherence between a point process and a field potential, described by Halliday et al. (1995).

Data analysis: STN spike synchronization to M1 broadband gamma activity. Because low frequencies $(<50 \mathrm{~Hz})$ predominate in the LFP power spectrum and its STA, we used additional methods to study synchronization between STN spikes and cortical broadband gamma activity. First, we visualized spike-broadband gamma interactions by plotting the spike-timed scalogram of the M1 LFP, in $1 \mathrm{~s}$ windows centered on the time of occurrence of STN spikes, from 0 to $300 \mathrm{~Hz}$, using a wavelet decomposition (see Fig. 4A). A Morlet wavelet of 5 cycles in width was convolved with the M1 LFP time series to estimate an amplitude and phase of the signal at each frequency for every point in time.

Next, we calculated an STN spike-M1 gamma modulation index $\mathrm{MI}_{\text {gamma }}$ using methods similar to those above for $\mathrm{MI}_{\mathrm{O}}$, but first isolating the $50-200 \mathrm{~Hz}$ portion of the cortical LFP spectrum (see also Fig. $4 B-E$ ). Before signal averaging, we bandpass filtered the raw cortical LFP at $50-200 \mathrm{~Hz}$ to isolate broadband gamma (100 tap FIR filter, implemented using MATLAB function filtfilt), and calculated the amplitude envelope of broadband gamma time series, from the magnitude of its analytic amplitude. This time series is referred to as gamma_AE. We computed the spike-timed average (STA) of gamma_AE, in $1 \mathrm{~s}$ windows centered on the time of occurrence of STN spikes ( $N=1000$ spikes). This STA waveform is indicative of the degree to which cortical broadband gamma activity is synchronized to the timing of STN spikes. We noted that, when spike-synchronized peaks in broadband gamma occurred, the amplitude of cortical broadband gamma was invariably modulated by the phase of a low-frequency rhythm between 4 and $30 \mathrm{~Hz}$ (see Fig. 4B). We therefore defined the spike-gamma modulation index $\mathrm{MI}_{\text {gamma }}$ in a manner that accounted for this behavior, using the amplitude envelope of the STA of gamma_AE. The method for determining $\mathrm{MI}_{\text {gamma }}$ was identical to steps 1-5 described above for calculating the spike-M1 oscillation modulation index $\mathrm{MI}_{\mathrm{O}}$, except that the analysis used the STA of gamma_AE rather than the STA of the unfiltered M1 LFP.

$\mathrm{MI}_{\text {gamma }}$ values $>3$ were considered to be statistically significant. For all spike-LFP pairs with a significant $\mathrm{MI}_{\text {gamma, }}$, we calculated: (1) the frequency of peak spectral power of the STA of gamma_AE (see Fig. 4B); (2) the instantaneous phase value of the bandpass-filtered STA of gamma_AE at spike time (time 0) (see Fig. 4D); (3) the latency from time 0 to the time of the peak of the amplitude envelope of the bandpass-filtered STA of gamma_AE (see Fig. 4D); and (4) the duration of the interval over which the amplitude envelope of the STA of gamma_AE crossed and stayed above the threshold of 3 SDs (see Fig. 4E).

For the subset of recordings that had modulation indices $>3$ and that had $>2000$ consecutive spikes available for analysis, we checked the effect of spike number $\left(500,1000\right.$, or 2000) on the modulation indices $\mathrm{MI}_{\mathrm{O}}$ and $\mathrm{MI}_{\text {gamma }}$. For most recordings, spike-M1 synchronization reached statistical significance using a spike number of 1000 , justifying the use of trains of 1000 spikes for most analyses in the study.

Statistical analysis of grouped data. Parameters calculated from the STN spike-cortical LFP synchronization analyses were summarized by their means and SDs, or medians and ranges depending on the normality of the data (tested using MATLAB function lillietest). Of note, for most study subjects, multiple STN-M1 paired recordings were sampled, from 
Table 1. Characteristics of Parkinson's disease subjects

\begin{tabular}{|c|c|c|c|c|c|c|c|c|c|c|c|}
\hline $\begin{array}{l}\text { Case } \\
\text { No. }\end{array}$ & $\begin{array}{l}\text { No. } \\
\text { cells }\end{array}$ & $\begin{array}{l}\text { Age } \\
\text { (years) }\end{array}$ & Gender & Handedness & $\begin{array}{l}\text { Disease } \\
\text { duration } \\
\text { (years) }\end{array}$ & $\begin{array}{l}\text { Side of } \\
\text { ECoG }\end{array}$ & $\begin{array}{l}\text { UPDRS III off } \\
\text { med total }\end{array}$ & $\begin{array}{l}\text { UPDRS III off } \\
\text { med contralat arm }{ }^{a}\end{array}$ & $\begin{array}{l}\text { UPDRS III off } \\
\text { med contralat body }\end{array}$ & $\begin{array}{l}\text { UPDRS III off } \\
\text { med contralat arm } \\
\text { rest tremor }\end{array}$ & LEED \\
\hline 1 & 5 & 54 & $M$ & Right & 6 & Left & 31 & 6 & 9 & 0 & 1420 \\
\hline 2 & 6 & 58 & $M$ & Right & 9 & Right & 53 & 9 & 14 & 0 & 1274 \\
\hline 3 & 4 & 73 & M & Right & 9 & Left & 30 & 6 & 9 & 0 & 2031 \\
\hline $4^{c}$ & 6 & 55 & $\mathrm{~F}$ & Right & 14 & Right & 22 & 5 & 7 & 0 & 1472 \\
\hline $5^{c}$ & 5 & 30 & M & Right & 7 & Right & 86 & 14 & 21 & 1 & 690 \\
\hline 6 & 6 & 62 & $\mathrm{~F}$ & Right & 16 & Right & 92 & 15 & 21 & 2 & 300 \\
\hline $7^{c}$ & 9 & 76 & M & Right & 12 & Left & 50 & 8 & 10 & 0 & 1994 \\
\hline 8 & 3 & 52 & M & Right & 11 & Right & 29 & 7 & 10 & 0 & 600 \\
\hline 9 & 2 & 57 & M & Left & 7 & Right & 36 & 8 & 11 & 0 & 1470 \\
\hline 10 & 4 & 63 & M & Left & 15 & Right & 48 & 10 & 15 & 3 & 1311 \\
\hline 11 & 2 & 61 & M & Right & 19 & Right & 31 & 6 & 9 & 0 & 954 \\
\hline 12 & 4 & 73 & M & Right & 20 & Right & 39 & 7 & 11 & 2 & 754 \\
\hline 13 & 4 & 67 & $\mathrm{~F}$ & Right & 19 & Left & 32 & 7 & 10 & 0 & 600 \\
\hline 14 & 3 & 46 & $M$ & Right & 7 & Left & 30 & 6 & 9 & 0 & 810 \\
\hline 15 & 3 & 64 & $M$ & Right & 8 & Left & 11 & 4 & 6 & 0 & 1300 \\
\hline 16 & 8 & 69 & $M$ & Right & 11 & Left & 68 & 11 & 16 & 0 & 160 \\
\hline 17 & 1 & 65 & $M$ & Right & 10 & Right & 24 & 4 & 5 & 0 & 1117 \\
\hline 18 & 2 & 74 & $M$ & Right & 10 & Right & 48 & 9 & 13 & 1 & 800 \\
\hline 19 & 4 & 59 & $M$ & Right & 13 & Left & 47 & 9 & 13 & 3 & 1924 \\
\hline 20 & 5 & 62 & $M$ & Right & 13 & Left & 42 & 5 & 9 & 3 & 1000 \\
\hline 21 & 3 & 56 & $M$ & Right & 5 & Right & 37 & 8 & 10 & 3 & 1294 \\
\hline 22 & 1 & 53 & $M$ & Right & 8 & Right & 30 & 6 & 8 & 2 & 1354 \\
\hline 23 & 3 & 51 & $M$ & Right & 12 & Left & 53 & 4 & 7 & 3 & 1280 \\
\hline 24 & 9 & 60 & $M$ & Right & 5 & Right & 33 & 7 & 8 & 3 & 1060 \\
\hline 25 & 1 & 61 & $\mathrm{~F}$ & Right & 12 & Left & 40 & 8 & 10 & 2 & 450 \\
\hline 26 & 4 & 78 & $M$ & Right & 11 & Left & 46 & 5 & 10 & 3 & 1776 \\
\hline 27 & 1 & 64 & $M$ & Right & 7 & Left & 38 & 11 & 18 & 3 & 340 \\
\hline 28 & 5 & 74 & $M$ & Right & 5 & Right & 33 & 9 & 12 & 3 & 0 \\
\hline 29 & 3 & 72 & $M$ & Left & 6 & Right & 43 & 5 & 11 & 4 & 0 \\
\hline Mean \pm SD & & $61.7 \pm 10.3$ & & & $10.6 \pm 4.3$ & & $41.4 \pm 17.3$ & $7.6 \pm 2.8$ & $11.1 \pm 4.0$ & $1.4 \pm 1.4$ & $1018 \pm 572$ \\
\hline
\end{tabular}

LEED, Levodopa equivalent dose; contralat, contralateral; med, medication.

${ }^{a}$ Sum of items 22-25, for arm contralateral to ECOG.

${ }^{b}$ Sum of UPDRS-III items 22-26, for arm and leg contralateral to ECOG.

'These patients had prominent off-period dystonia.

Table 2. Characteristics of primary dystonia patients

\begin{tabular}{|c|c|c|c|c|c|c|c|c|c|c|c|}
\hline $\begin{array}{l}\text { Case } \\
\text { No. }\end{array}$ & $\begin{array}{l}\text { No. } \\
\text { cells }\end{array}$ & $\begin{array}{l}\text { Age } \\
\text { (years) }\end{array}$ & Gender & Handedness & $\begin{array}{l}\text { Disease } \\
\text { duration } \\
\text { (years) }\end{array}$ & $\begin{array}{l}\text { Side of } \\
\text { ECoG }\end{array}$ & $\begin{array}{l}\text { BFMDRS } \\
\text { movement } \\
\text { total }\end{array}$ & $\begin{array}{l}\text { BFMDRS } \\
\text { movement } \\
\text { contralat arm }\end{array}$ & $\begin{array}{l}\text { BFMDRS } \\
\text { movement } \\
\text { contralat body }\end{array}$ & $\begin{array}{l}\text { TWSTRS } \\
\text { severity }\end{array}$ & $\begin{array}{l}\text { Medications } \\
\text { (daily total, mg) }\end{array}$ \\
\hline 1 & 3 & 40 & $\mathrm{~F}$ & Right & 9 & Left & 8 & 0 & 0 & 24 & Clonazepam 1 \\
\hline 2 & 3 & 48 & $M$ & Right & 4 & Right & 8 & 0 & 0 & 22 & None \\
\hline 3 & 5 & 68 & $\mathrm{~F}$ & Left & 10 & Left & 22 & 0 & 0 & 17 & $\begin{array}{l}\text { Baclofen } 10 \\
\text { Diazepam } 5 \\
\text { Ethopropazine } 125\end{array}$ \\
\hline 4 & 4 & 71 & $M$ & Right & 30 & Left & 13 & 0 & 0 & 23 & Lorazepam 3 \\
\hline 5 & 3 & 63 & M & Right & 10 & Right & 22.5 & 2 & 2 & 13 & $\begin{array}{l}\text { Clonazepam } 2 \\
\text { Propranolol } 160\end{array}$ \\
\hline 6 & 8 & 53 & M & Right & 25 & Left & 15 & 4 & 4 & 21 & $\begin{array}{l}\text { Clonazepam } 3 \\
\text { Alprazolam } 3\end{array}$ \\
\hline Mean $\pm S D$ & & $57.2 \pm 12.2$ & & & $14.7 \pm 10.3$ & & $14.8 \pm 6.4$ & $1 \pm 1.7$ & $1 \pm 1.7$ & $20 \pm 4.2$ & \\
\hline
\end{tabular}

contralat, Contralateral.

different locations within the motor territory of the STN (Tables 1 and 2). We did not assume a priori that different recordings from the same subject were statistically independent. Therefore, for comparisons between disease groups (see Fig. 5A), results from standard statistical tests (Wilcoxon rank sum test) were also checked using a general estimation equations method (GEE, SPSS Software), with subject number as a within-subjects variable to account for potential clustering of withinsubjects data (Hanley et al., 2003). Similarly, correlations of physiological measures with symptom severity (see Figs. $3 E, 4 F$ ) were performed both with linear regression (assuming independence of all samples), and using a GEE model that did not assume sample independence within subjects. Phase distributions were analyzed for their difference from a uniform distribution using the Rayleigh test (Moran et al., 2008). Categorical data were analyzed using $\chi^{2}$ or Fisher's exact tests.

\section{Results}

Study subjects

Characteristics of the study subjects, including preoperative medications, are provided in Tables 1 and 2. There were 29 sub- 
A

$$
\begin{aligned}
& \text { STN unit } \\
& \text { discharge }
\end{aligned}
$$

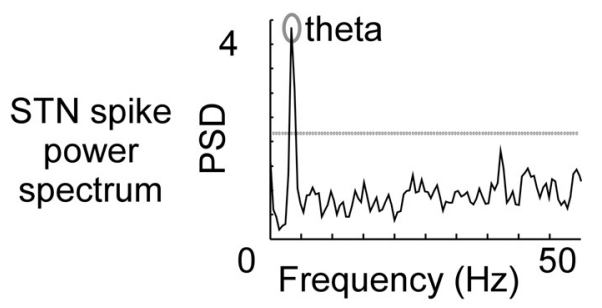

B

M1 LFP
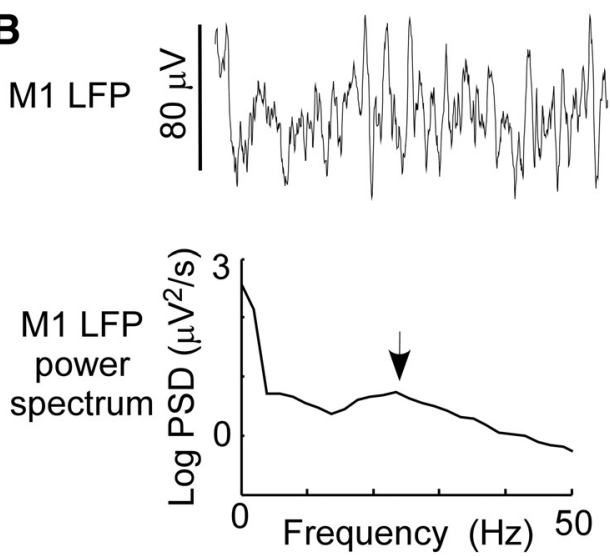

theta and beta oscillations
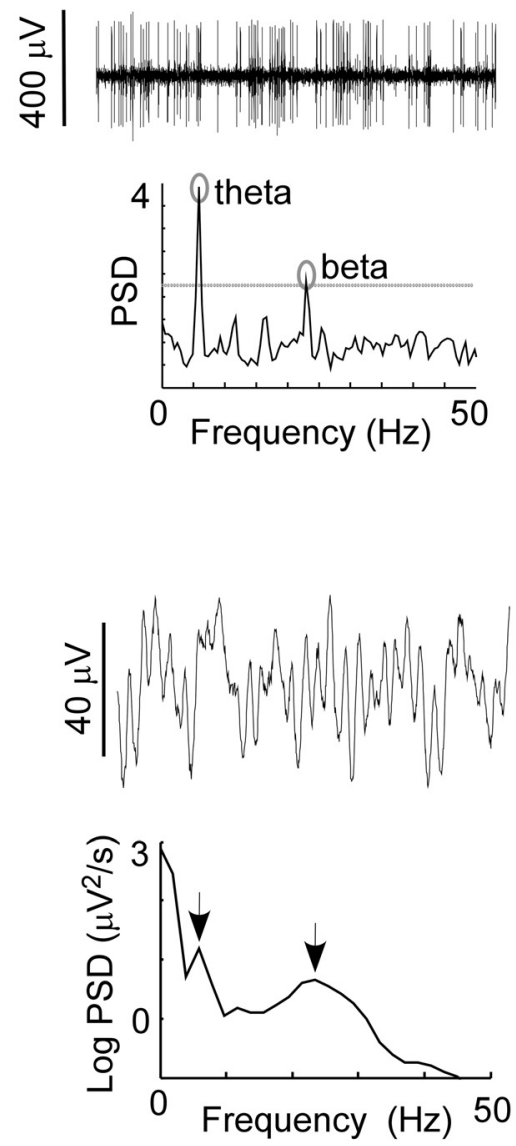

beta oscillations
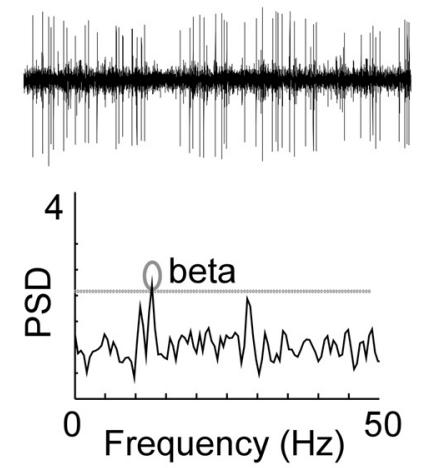

\section{Oscillations in STN spike train}

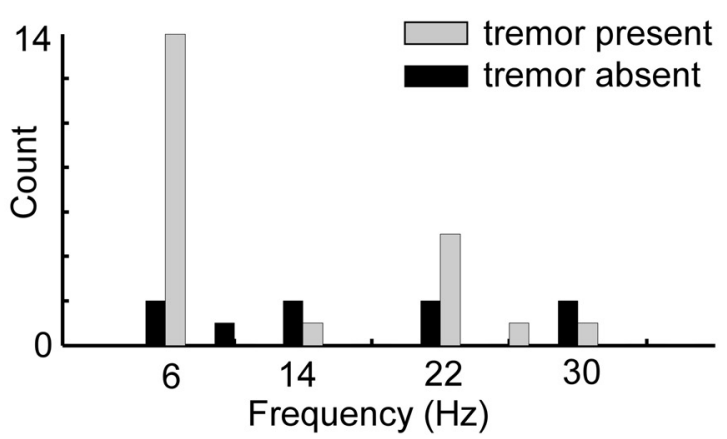

D Peaks in M1 power spectrum

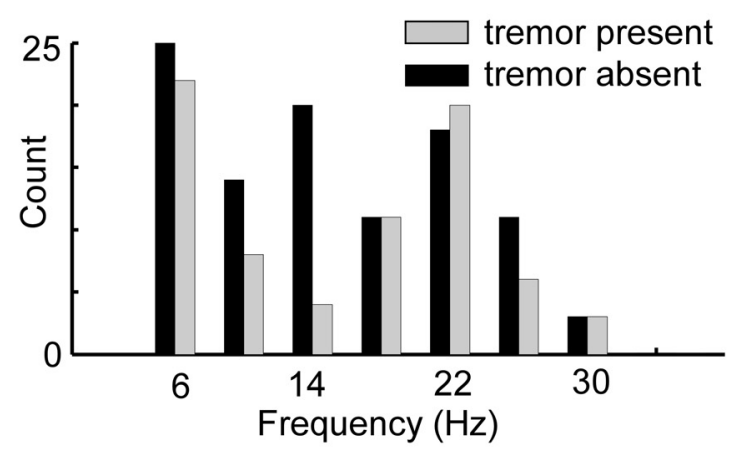

Figure 2. Oscillatory activity in STN single-unit discharge and in the M1 LFP between 4 and $50 \mathrm{~Hz}$, in PD. A, Examples of units with tremor frequency, beta frequency, and both types of oscillatory activity. A 1 s recording of neuronal activity is shown with the frequency spectrum for the spike train below. The gray dotted line is the significance threshold, and gray circles indicate statistically significant peaks in the power spectrum (Rivlin-Etzion et al., 2006). B, Simultaneously recorded M1 LFPs, and their power spectra are shown in bottom row for each example. Vertical arrows show peaks in the power spectrum in theta or beta ranges. $\boldsymbol{C}, \boldsymbol{D}$, Distribution of single-unit oscillation frequencies $(\boldsymbol{C})$ and peak frequencies in the M1 LFP power spectrum (D) across all PD subjects, segregated according to the presence or absence of tremor during the recording.

jects in the PD group, and six in the dystonia group. Primary dystonia patients had mainly craniocervical involvement, with minimal symptoms in the arm contralateral to the side of recording in most subjects. Two dystonia subjects had action-induced arm tremor or writer's cramp, resulting in nonzero BFMDRS scores for the contralateral arm (Table 2), but did not have tremor or dystonic posturing of limbs at rest.

\section{Oscillations in STN unit discharge and M1 LFPs in PD}

In PD patients, a total of 116 simultaneous recordings of STN single units with M1 LFPs were analyzed. Forty-six of these re- cordings occurred during contralateral arm tremor, whereas 70 occurred during no detectable contralateral arm tremor. The spike firing rate (mean \pm STD) was $35.6 \pm 14.1 \mathrm{~Hz}$. Twenty-eight units had significant oscillations in the spike train in the $4-50 \mathrm{~Hz}$ range (Fig. $2 A, C$ ). For subsequent analyses, oscillations were further subcategorized as beta frequency $(12-30 \mathrm{~Hz})$, theta-alpha frequency $(4-12 \mathrm{~Hz}$, which includes tremor frequency and its first harmonic), or neither (Table 3). The distribution of singleunit oscillation frequencies was bimodal, with one beta cluster and one theta-alpha cluster, consistent with prior reports (Levy et al., 2000; Rodriguez-Oroz et al., 2001; Moran et al., 2008). Two 
Table 3. Proportion of recordings with different types of oscillatory behavior, categorized by presence of or absence of tremor

\begin{tabular}{|c|c|c|c|c|c|c|c|c|c|c|}
\hline \multirow[b]{2}{*}{ Type of oscillation } & \multirow[b]{2}{*}{ No. recordings } & \multicolumn{3}{|l|}{$4-50 \mathrm{~Hz}$} & \multicolumn{3}{|c|}{$4-12 \mathrm{~Hz}^{a}$} & \multicolumn{3}{|c|}{$12-30 \mathrm{~Hz}^{a}$} \\
\hline & & Tremor & No tremor & $p$ value $^{b}$ & Tremor & No tremor & $p$ value $^{b}$ & Tremor & No tremor & $p$ value $^{b}$ \\
\hline Single unit oscillations & 116 & $19 / 46$ & 9/70 & 0.0005 & $13 / 46$ & $3 / 70$ & 0.0002 & $8 / 46$ & $5 / 70$ & 0.087 \\
\hline Peak in M1 power spectrum & $108^{c}$ & $44 / 44$ & $64 / 64$ & 1.00 & $30 / 44$ & $39 / 64$ & 0.441 & $44 / 44$ & $63 / 64$ & 1.00 (two sided) \\
\hline Mlo & 116 & $25 / 46$ & $31 / 70$ & 0.289 & $14 / 46$ & $1 / 70$ & $<0.0001$ & $12 / 46$ & $29 / 70$ & 0.091 \\
\hline $\mathrm{MI}_{\mathrm{gamma}}$ & 116 & $9 / 46$ & $37 / 70$ & 0.0003 & $4 / 46$ & $20 / 70$ & 0.010 & $5 / 46$ & $18 / 70$ & 0.050 \\
\hline
\end{tabular}

Bold indicates significant $p$ values.

${ }^{a}$ Some recordings had significant oscillatory activity at multiple frequencies. Thus, some cells counted in both the 4-12 and 12-30 Hz frequency bands.

${ }^{b} p$ values were derived from $\chi^{2}$ tests except where the expected values in any category were $<5$; then Fisher's exact test was used.

'For all cell or cell-LFP paired recordings, there were 116 total recordings. For M1 recordings, there were only 108 unique recordings, because for eight paired spike-LFP recordings, two cells were isolated from the same recordings.

units oscillated in both frequency bands (Fig. $2 A$, middle example). Oscillations near tremor frequency were found in some recordings in the absence of detectable tremor during the recording, but were more likely to occur when tremor was present (details in Table 3).

Power spectra of the M1 LFP (Fig. 2B) were inspected for peaks (local maxima) in the beta and tremor bands. All but one M1 recording had a spectral peak in the beta band, whereas 68 also had a separate peak in the theta or alpha frequency bands (Fig. 2B,D). The presence or absence of contralateral limb tremor during the recording was not predictive of the presence or absence of a tremor frequency peak in the M1 LFP power spectrum (Fig. 2D; Table 3).

\section{Synchronization of STN spikes to motor cortex oscillations at $4-50 \mathrm{~Hz}$ in PD}

Synchronization of STN single units to cortical rhythms was examined primarily by analysis of STN spike-timed averages of the cortical LFP. The STA waveform is indicative of the degree to which cortical oscillations are phase synchronized to the timing of STN spikes. An illustrative example is shown in Figure $3 A, B$. When compared across all five cortical LFP recording pairs (Fig. $3 B$ ), spike-cortex synchronization was always maximal in a contact pair that covered M1. The methods of quantifying the frequency, phase, and magnitude (modulation index $\mathrm{MI}_{\mathrm{O}}$ ), of the STN spike synchronization to M1 LFP oscillations, are shown in Figure $3 B-D$. The magnitude of spike-M1 LFP synchronization correlated with the severity of contralateral bradykinesia (using preoperative UPDRS-III bradykinesia scores) (Fig. 3E), and this was true whether or not within-subject recordings were treated as statistically independent ( $p$ value for linear correlation of independent samples of 0.015 with Pearson's $r$ of 0.224 , versus $p$ value from the GEE model of 0.001 with a beta coefficient of 0.37 ).

For those spike-M1 pairs with significant modulation (defined as $\mathrm{MI}_{\mathrm{O}}>3,56$ recordings), the latency, frequency, and phase relationships between spike and LFP are shown in Figure $3 F-H$. Three recordings had significant spike-LFP modulation at two different frequencies. The median onset of spike-LFP synchrony was $103 \mathrm{~ms}$ before the spike time $(p<0.001$ for difference from zero, nonparametric sign test) and the median time of peak modulation (defined as shown in Fig. 3C) was $18.5 \mathrm{~ms}$ before the spike time (not significantly different from zero by the sign test) (Fig. $3 F$ ). The distribution of STN-M1 LFP synchronization frequencies, derived from the power spectra of the spike-timed averages, showed clusters in the theta and beta bands. (Fig. 3G). STN-M1 LFP synchronization at or near tremor frequency (4-12 $\mathrm{Hz}$ ) was much more prominent when limb tremor was present during the recording (Table 3). Similar results were found when STN spike-M1 LFP coherence was analyzed by the Halliday method rather than by using spike time averages of M1 (data not shown). The distribution of phases for STN-M1 synchronization was significantly different from a uniform distribution $(p=0.001$, Rayleigh test), with a mean phase angle of 1.6 radians, corresponding to the falling slope of the bandpass-filtered M1 LFP sinusoid (Fig. $3 C, H)$. STN spike synchronization to the M1 LFP was not restricted to neurons that had prominent arm related activity during intraoperative somatosensory examination, but was also found for neurons whose discharge was primarily modulated by leg movement or had no detectable response to passive movement $\left(p=0.83, \chi^{2}\right)$ (Fig. $3 I$ ), notwithstanding the fact that cortical recordings were made exclusively over the arm territory of M1.

\section{STN spike-cortical gamma synchronization}

The use of the spike-timed LFP average for analysis of spike-M1 synchrony (Fig. 3) mainly explores the low-frequency range of the LFP power spectrum $(<50 \mathrm{~Hz})$, as these frequencies predominate in the LFP and in its STA. However, we were also interested in synchronization between STN spikes and cortical broadband gamma activity $(50-200 \mathrm{~Hz})$, as the latter is thought to reflect underlying cortical spiking activity (Manning et al., 2009), and therefore offers a means of exploring the relationship between STN spiking and cortical spiking. To visualize STN spike-M1 gamma interactions, we plotted spike-timed scalograms, illustrated for one representative example in Figure $4 A$. In the scalogram, spectral power is normalized separately at each frequency (to the mean of its wavelet convolution), allowing visual examination of gamma frequencies that are too small to observe in the spike-timed LFP average illustrated in Figure 3.

Inspection of spike-timed M1 scalograms revealed synchronization of broadband gamma with STN spikes, in a highly distinctive pattern: waves of increased M1 broadband gamma activity, alternating with troughs of broadband gamma. The occurrence of this pattern in the scalogram implies that there are epochs of cortical phase-amplitude coupling whose phase frequency is itself synchronized to the timing of STN spikes. The highest amplitude gamma waves typically preceded the time of occurrence of STN spikes. This oscillating pattern of broadband gamma activity had an amplitude envelope typically in the beta, alpha, or theta range. The frequency range of broadband gamma that was most prominently synchronized to STN spiking was $50-200 \mathrm{~Hz}$ (Fig. 4A), so this region of the spectrum was used for further quantitative analysis.

Figure $4 B-E$ shows the method of quantifying the parameters of STN spike-M1 gamma synchronization, including the frequency and phase of the amplitude envelope for gamma activity, the latency from peak gamma modulation to STN spike time, and the overall strength of the spike-gamma interaction (modulation index $\mathrm{MI}_{\text {gamma }}$ ). The magnitude of spike-M1 gamma synchronization did not correlate with lateralized total preoperative UPDRS scores or with contralateral bradykinesia scores, but did have a modest negative correlation with contralateral tremor 
A STN unit discharge

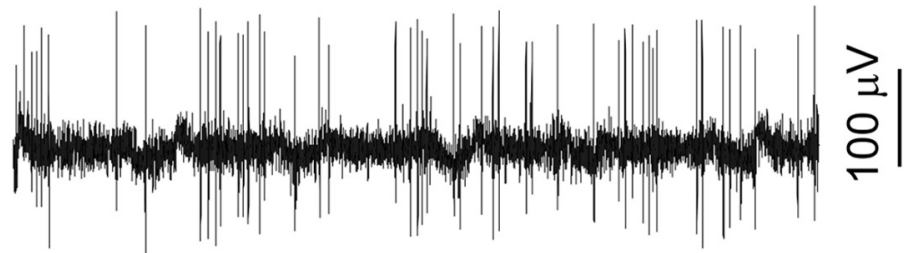

M1 LFP

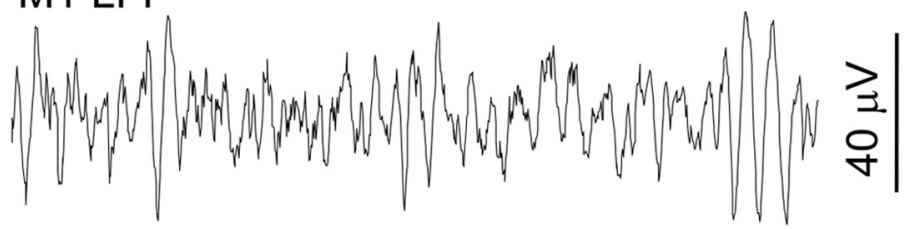

$200 \mathrm{msec}$

B

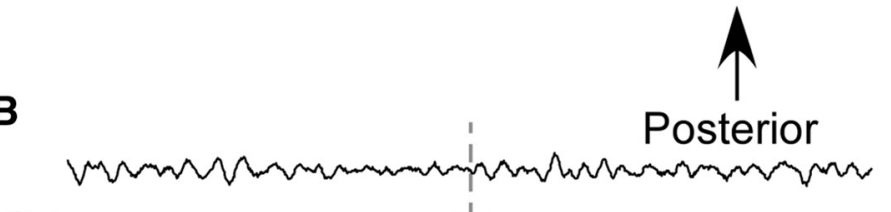

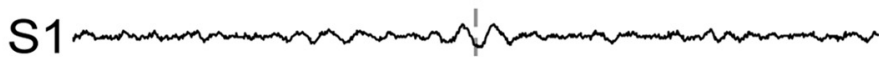

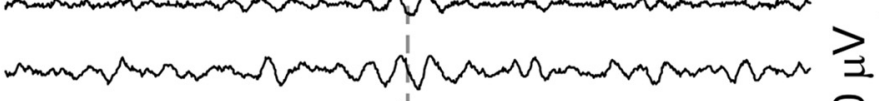

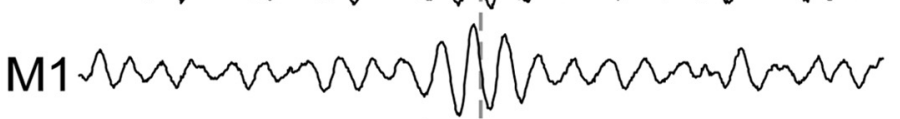

-500

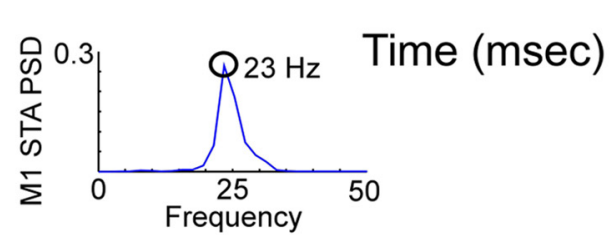

C Filtered STA and

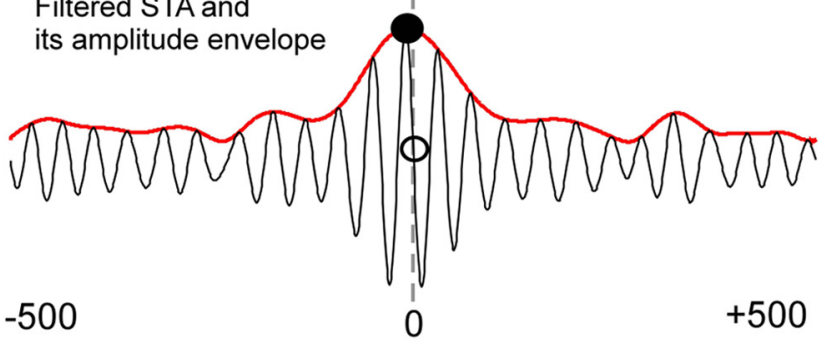

$-500$

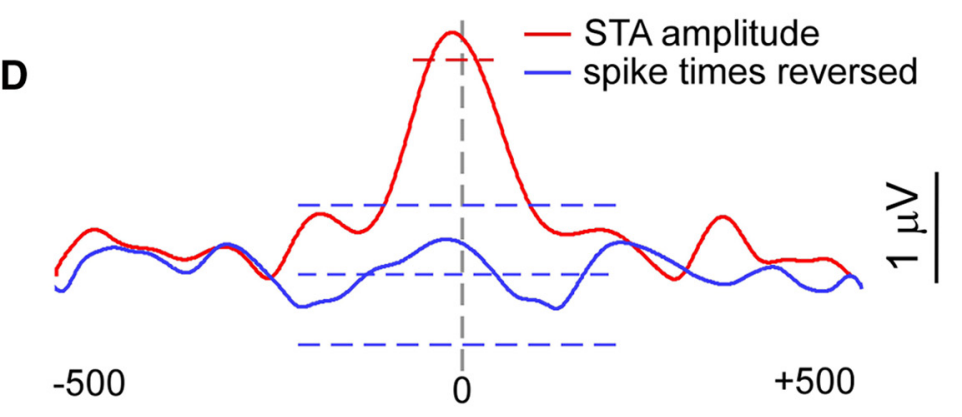

E

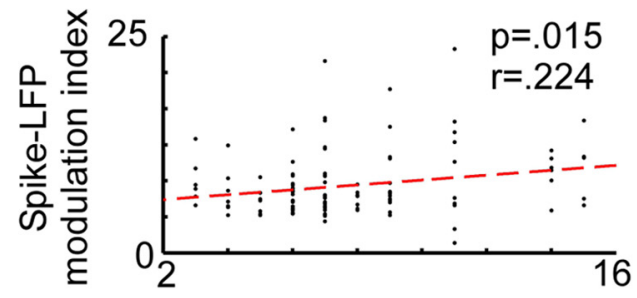

Contralateral bradykinesia score

$\mathbf{F}$

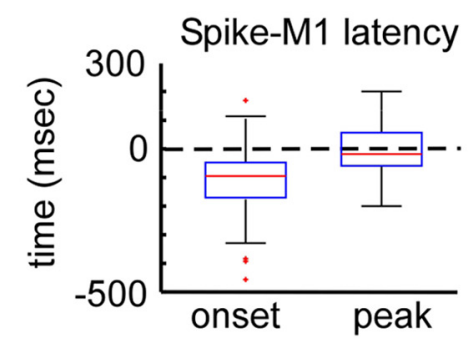

G Synchronization frequency

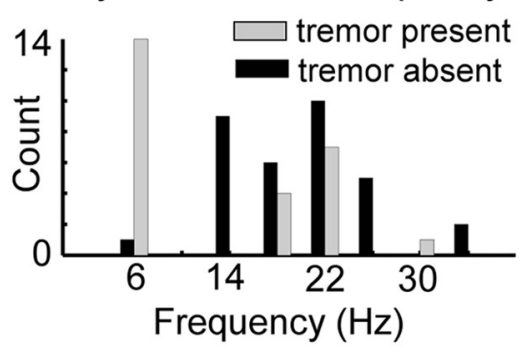

H
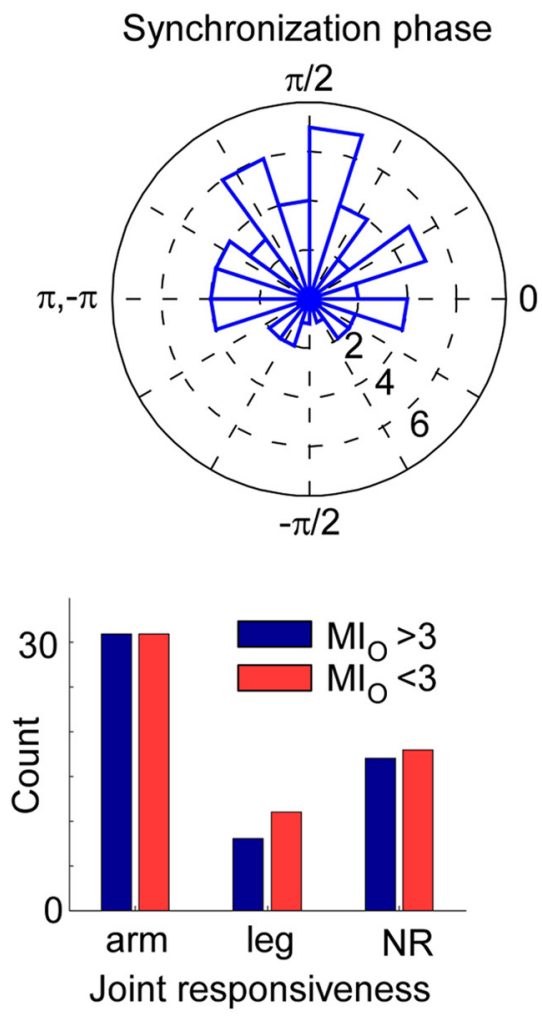
scores (Fig. 4F). These results were invariant to the statistical method used for correlation (treating all recordings as independent samples, $p=0.038$ with $r$ of -0.193 , or treating withinsubjects recordings as nonindependent samples in a GEE model, $p=0.043$ and beta coefficient of -0.226 , for the inverse correlation with tremor). For those spike-M1 pairs with significant modulation of $\mathrm{M} 1$ gamma (defined as $\mathrm{MI}_{\text {gamma }}>3$, 46 recordings), the latency, frequency, and phase relationships for synchronization of STN spikes to the M1 gamma amplitude envelope are shown in Figure $4 G-I$. The median onset of spikegamma synchrony was $107.1 \mathrm{~ms}$ before the spike time $(p<0.001$ for difference from zero, nonparametric sign test) and the median time of peak modulation (defined as shown in Fig. $4 D$ ) was $48 \mathrm{~ms}$ before the spike time ( $p=0.05$ for difference from zero, sign test, Fig. $4 G$ ). The distribution of frequencies for the spikesynchronized M1 gamma envelope, derived from the power spectra of the spike-timed average of gamma activity, shows that the gamma amplitude envelope oscillated most prominently in the theta and beta bands (Fig. $4 H$ ). Spike-gamma envelope synchronization at any frequency, and especially at beta frequencies, was more likely to occur in the absence of contralateral tremor (Table $3)$. This contrasts with the relationship between spike-LFP synchronization and contralateral tremor (Table 3), and suggests a relationship between symptom profile and the type of synchronization $\left(\mathrm{MI}_{\mathrm{O}}\right.$ vs $\left.\mathrm{MI}_{\text {gamma }}\right)$, not just the frequency, of basalganglia-cortex interactions. The distribution of phases for STN-M1 gamma envelope synchronization showed variable phase relationships that did not differ from a uniform distribution ( $p>0.05$, Rayleigh test) (Fig. 4I). STN spike synchronization to M1 gamma was not restricted to neurons that had prominent arm related activity during intraoperative somatosensory examination $\left(p=0.72, \chi^{2}\right)$ (Fig. $\left.3 J\right)$.

\section{Disease-specific patterns of STN-M1 synchronization}

Although normal control data for invasive recordings cannot be obtained from humans, we were able to assess the disease specificity of our findings in PD subjects by comparison with patients with primary craniocervical dystonia (Fig. 5), who also underwent placement of stimulators into the STN (Ostrem et al., 2011). Twenty-six spike-LFP pairs from six dystonia patients were avail-

\footnotetext{
$\leftarrow$

Figure 3. Synchronization of STN spiking with cortical LFP oscillations in PD. $\boldsymbol{A}$, Example of simultaneously recorded STN unit activity (top trace) and M1 LFP (bottom trace), $>1$ s. $\boldsymbol{B}$, Example of STA of the cortical LFP, for all five contact pairs from most posterior (top trace) to most anterior (bottom trace; $N=1000$ spikes). The inset shows the power spectrum of the M1 STA. C, Method of determining phase and latency of M1 STA with respect to STN spike time. Black line shows bandpass-filtered STA, red line shows its amplitude envelope, and vertical dashed line marks spike time. Open circle, the zero crossing of the bandpass-filtered STA (phase $=1.4$ radians). Closed circle, peak of the amplitude envelope, occurring at a latency of 7 ms before spike occurrence. $\boldsymbol{D}$, Method of determining the spike-M1 LFP oscillation modulation index $\mathrm{MI}_{0}$. Red line is the amplitude envelope of the bandpass-filtered STA, with dotted horizontal bar showing average value (during a $100 \mathrm{~ms}$ window centered on its peak). Blue line is the amplitude envelope of the reverse time STA, with horizontal lines showing mean \pm 3 SDs during a $400 \mathrm{~ms}$ window. The $\mathrm{M1}_{0}$ for this unit-M1 pair is 9.2 in $z$-score units, and the STA frequency is $23.4 \mathrm{~Hz}$. E, Positive correlation between $\mathrm{MI}_{0}$ and preoperative UPDRS bradykinesia scores for the contralateral body. $\boldsymbol{F}$, Box plots showing the distribution of time of onset, and time of peak effect, of spike-M1 gamma synchronization. $\mathbf{G}$, Histogram showing the distribution of peak frequencies for the STN spike time averaged M1 LFP in PD patients with and without tremor during the recording. $\boldsymbol{H}$, Phase histogram, showing the distribution of phases for the spike time averaged M1 LFP waveform with respect to STN spike time. Data in $\boldsymbol{G}$ and $\boldsymbol{H}$ are only for recordings with $\mathrm{Ml}_{0} \mathrm{~s}$ that reached statistical significance. $I$, Bar graph showing the numbers of recordings with and without significant $\mathrm{MI}_{0}$, segregated by the responsiveness of STN cells to contralateral limb movement. NR, No response.
}

able for analysis. For STN synchronization to M1 oscillations in the $4-50 \mathrm{~Hz}$ range, the magnitude of synchronization $\left(\mathrm{MI}_{\mathrm{O}}\right)$ was less than in $\mathrm{PD}(p=0.005$ for Wilcoxon rank sum test and 0.009 for GEE model) (Fig. 5A, left). Six spike-LFP pairs in dystonia patients had significant synchronization $\left(\mathrm{MI}_{\mathrm{O}}>3\right)$, in the theta, alpha, or beta ranges (Fig. $5 B$, left), but the proportion of all recordings with significant beta range spike-LFP synchronization was less than for PD ( 4 of 26 in dystonia vs 41 of 116 in PD, $p=$ $\left.0.05, \chi^{2}\right)$. For STN synchronization to M1 gamma activity, six paired recordings in dystonia also showed waves of amplitude modulated broadband activity, slightly preceding the time of occurrence of STN spikes, one of which occurred at two different frequencies of the sinusoidal amplitude envelope (Fig. $5 B$, right). However, the pattern of spike-gamma synchronization was strikingly different from that seen in $\mathrm{PD}$, in that the frequency of the sinusoidal amplitude envelope for broadband gamma was never in the beta band in dystonia patients but was commonly in the beta band in PD patients ( 0 of 26 in dystonia vs 23 of 116 in PD, $p=0.008$ by Fisher's exact test).

\section{Relation between spike-M1 LFP rhythm modulation and spike-M1 gamma modulation}

Two forms of spike-M1 synchronization were studied here: spike synchronization to M1 rhythms $(4-50 \mathrm{~Hz})$, and spike synchronization to M1 gamma $(50-200 \mathrm{~Hz})$. Several lines of evidence suggest that these represent distinct phenomena. First, across all recordings with a significant $\mathrm{MI}_{\mathrm{O}}$ or significant $\mathrm{MI}_{\text {gamma }}$, the value of these modulation indices were not correlated (Fig. $6 A, B)$. Second, although the spike-gamma modulation had an oscillating amplitude envelope (Fig. $4 A-C$ ), the frequency of the amplitude envelope for the STN spike-M1 gamma modulation did not correlate with the frequency for spike-M1 rhythm modulation (Fig. 6B). Thus, the mechanisms for generating these two modes of synchronization may be at least partly independent.

\section{Discussion}

To examine cortex-basal ganglia interaction in humans with movement disorders, we recorded M1 local field potentials simultaneously with STN single-unit activity in patients undergoing STN DBS implantation for Parkinson's disease, as well as in a comparison group with primary craniocervical dystonia. LFPs represent summed, synchronized subthreshold activity in presynaptic and postsynaptic elements near the recording electrode, and are increasingly used in studies of neuronal synchronization in the motor system in normal, as well as disease states (Murthy and Fetz, 1996; Goldberg et al., 2004; Hammond et al., 2007). In general, the phase of LFP oscillations biases the probability of spike firing. In the normal state, this modulation is dynamic and task specific, representing a flexible mechanism whereby LFP oscillations can link functionally related brain areas (Fries, 2005; Leventhal et al., 2012).

\section{STN spike-M1 rhythm synchronization}

Excessive neuronal oscillatory activity within specific basal ganglia nuclei is a well documented feature in parkinsonian animal models as well as in human PD (Dostrovsky and Bergman, 2004; Hammond et al., 2007). Similarly, simultaneously recorded neurons within the subthalamic nucleus or internal globus pallidus have oscillations that are strongly synchronized (Nini et al., 1995; Levy et al., 2002a; Hanson et al., 2012), and basal ganglia neurons tend to be synchronized to LFPs recorded in the same structure (Kuhn et al., 2005; Moran et al., 2008). However, the relation of basal ganglia oscillations to cortical activity is less well studied. In 

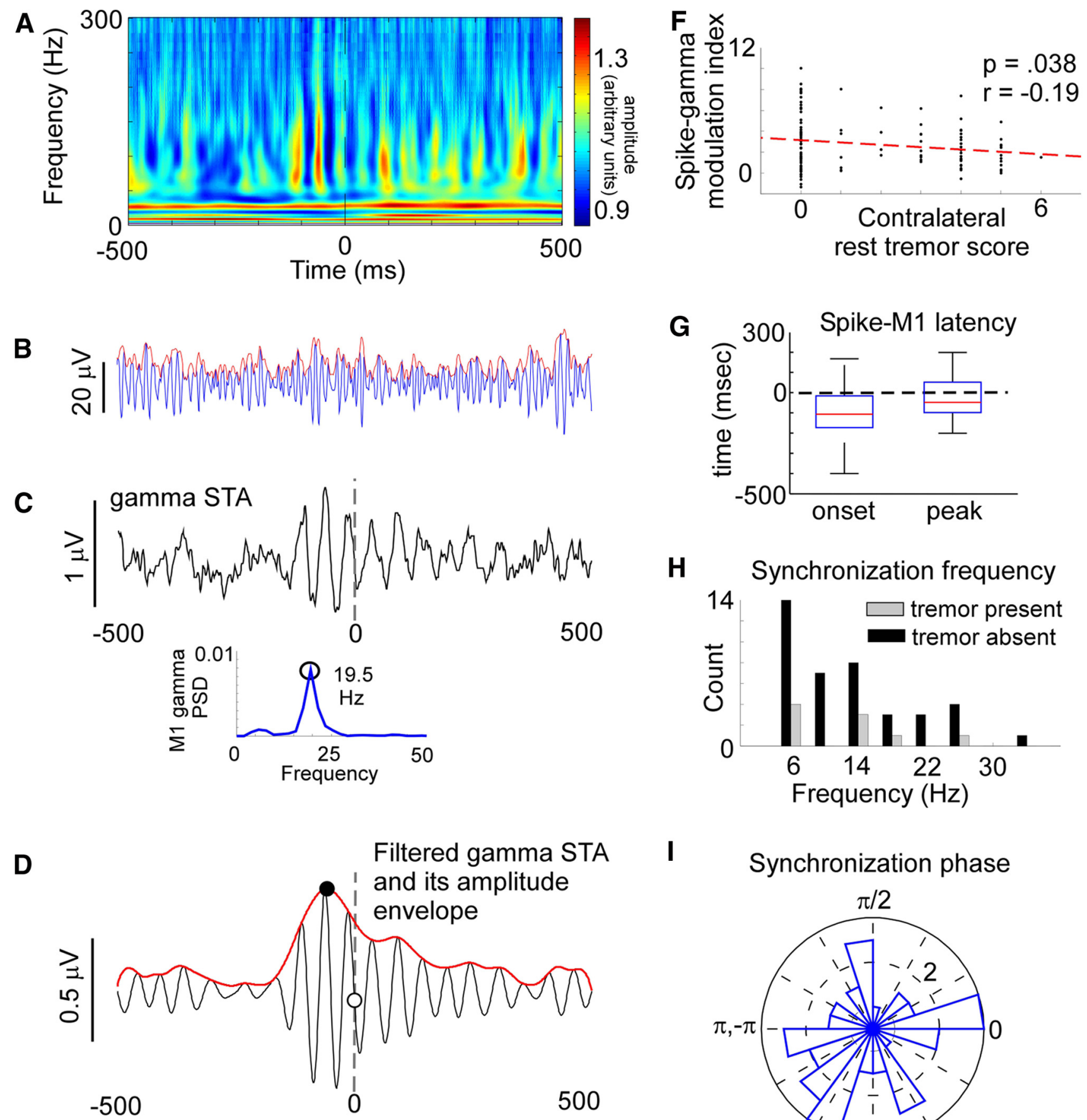

500

Synchronization phase
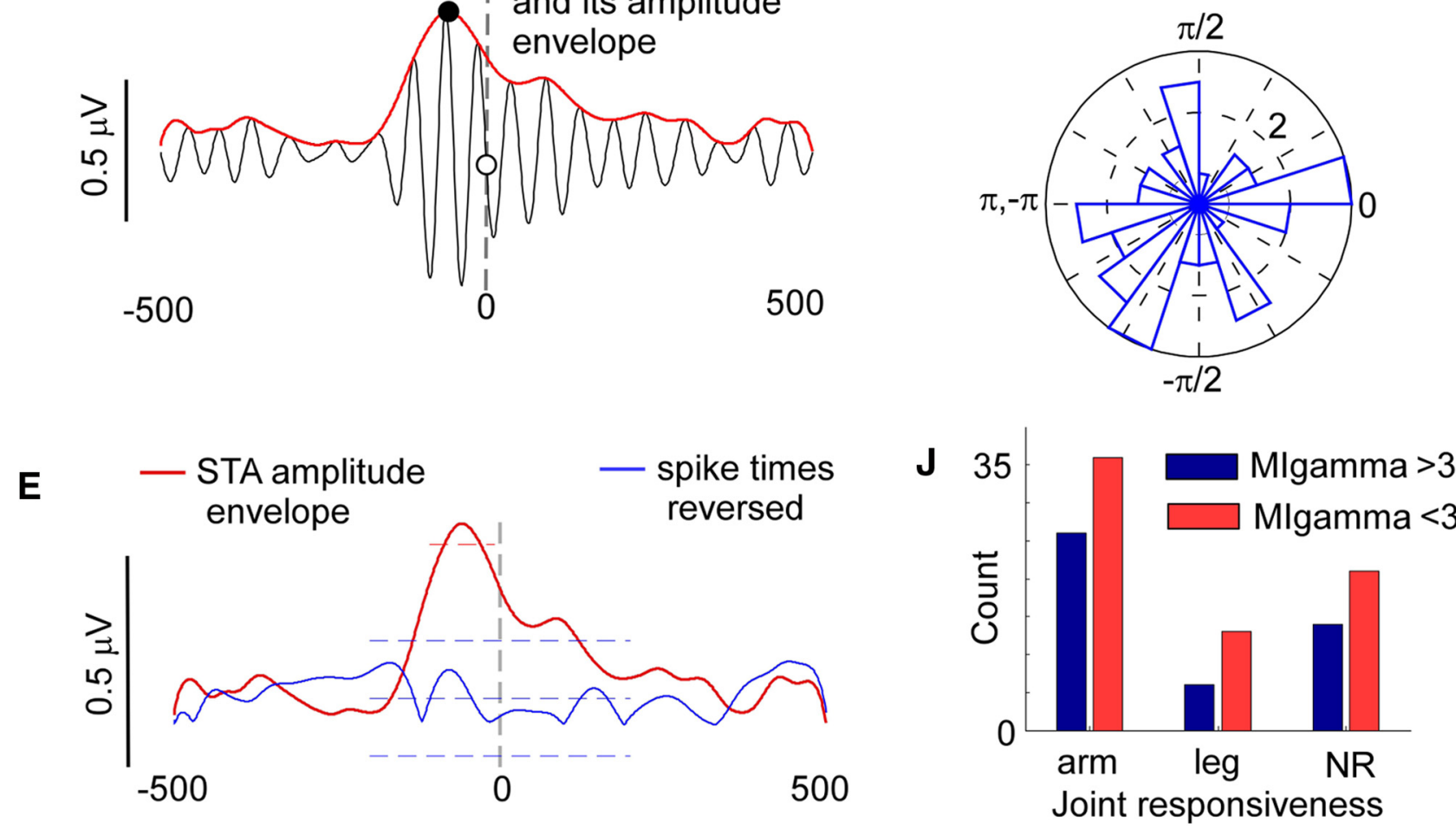
humans, interactions between cortex and basal ganglia at fast time scales have been primarily studied by recording basal ganglia LFPs in conjunction with scalp electroencephalography (Williams et al., 2002; Fogelson et al., 2006; Lalo et al., 2008; Eusebio et al., 2009) or magnetoencephalography (Litvak et al., 2011). These studies have elucidated specific patterns of cortex-basal ganglia coherence, but in general have not used nonparkinsonian comparison groups.

Here, we provide the first demonstration of the synchronization of basal ganglia spiking with cortical oscillations in humans with PD. This behavior is relatively specific to the parkinsonian state, as it is less prominent in a different movement disorder of basal ganglia origin, primary craniocervical dystonia. We show that synchronization occurs across a broad range of low-frequency rhythms (theta, alpha, and beta). Spike-LFP synchronization at tremor (theta) frequency is much more likely when tremor is present during the recordings (Fig. $3 G$ ). However, tremor frequency oscillations in spike discharge and M1 LFPs do occur in the absence of tremor (Fig. 2), suggesting that neuronal oscillatory phenomena at tremor frequency are not exclusively a consequence of tremorfrequency peripheral input. It is possible that tremor frequency discharges at different points in the circuit represent a "parkinsonian endophenotype," but that the clinical manifestation of tremor specifically requires synchronization of these oscillations between basal ganglia and cortex.

$\leftarrow$

Figure 4. Synchronization of STN spiking with M1 broadband gamma activity in PD. A, Example of spike-timed scalogram, showing cortical activity aligned to the time of STN spikes. Color-scale represents the amplitude of oscillatory activity, normalized separately for each frequency. $\boldsymbol{B}$, One-second segment of $\mathrm{M} 1 \mathrm{ECOG}$, bandpass filtered to isolate broadband gamma component ( $50-200 \mathrm{~Hz}$ ) (blue line), with its amplitude envelope (red line). C, Spike-timed average of the $\mathrm{M} 1$ broadband amplitude envelope (1000 spikes), showing amplitude modulation of the gamma component (phase-amplitude coupling) preceding and overlapping with the timing of STN spikes. The inset shows the PSD of the spike-timed average of the M1 gamma amplitude. $\boldsymbol{D}$, Method of determining the latency and phase of the M1 gamma amplitude envelope with respect to STN spike time. Black line shows the STN spike time average of the broadband gamma component $(50-200 \mathrm{~Hz}$ ) of the M1 LFP (after bandpass filtering around its peak frequency). Open circle marks the phase of the signal at time 0 ( 1.7 radians in this example). Red line shows the amplitude envelope of the spike time average of the broadband gamma component. Filled circle shows the peak of amplitude envelope, occurring at a latency of $58 \mathrm{~ms}$ before spike occurrence in this example. $E$, Method of determining the spike-gamma modulation index $\mathrm{Ml}_{\text {gamma. }}$. Solid red line is the solid red line in $\boldsymbol{D}$, with horizontal dotted red bar showing average value over a $100 \mathrm{~ms}$ interval around the peak. Blue line is the amplitude envelope of the reverse-timed spike time average of $\mathrm{M} 1$ broadband gamma activity, with horizontal dotted blue lines showing mean \pm 3 SDs ( MI $_{\text {gamma }}$ is 8.0 in this example). $\boldsymbol{F}$, Negative correlation between $\mathrm{MI}_{\mathrm{gamma}}$ and preoperative UPDRS resting tremor scores for the contralateral body. G, Box plots showing the distribution of time of onset, and time of peak effect, of spike-M1 gamma synchronization. $\boldsymbol{H}, \boldsymbol{I}$, Histograms showing the distribution of frequencies $(\boldsymbol{H})$ and phases $(\boldsymbol{I})$ for the oscillatory amplitude envelope of the spike time average of the M1 gamma component, for recordings whose $\mathrm{Ml}_{0} \mathrm{~s}$ reached statistical significance. Data in $\boldsymbol{H}$ are segregated by the presence or absence of tremor during the recording. J, Bar graph showing the number of recordings with and without significant $\mathrm{MI}_{\text {gamma, }}$, segregated by the responsiveness of STN cells to contralateral limb movement. NR, No response.

\section{Spike-gamma synchronization}
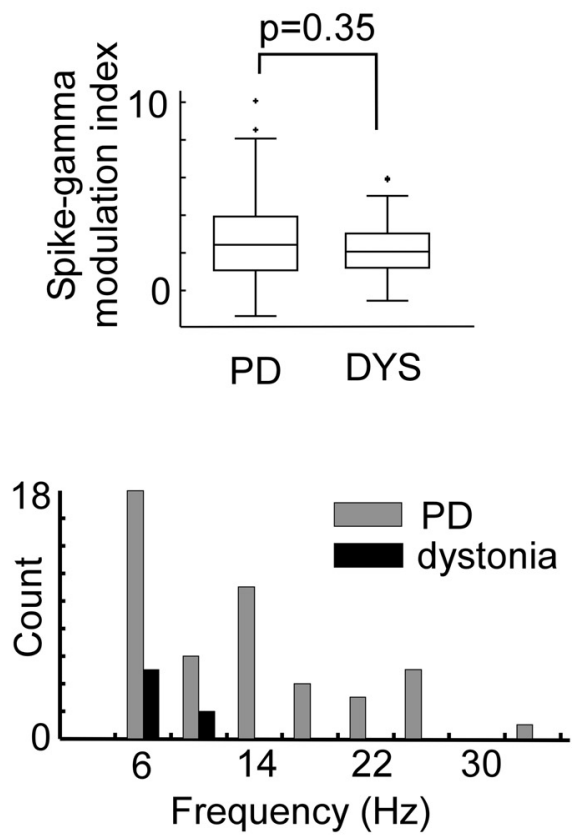

Figure 5. Comparison of STN spike-M1 synchronization in PD versus primary craniocervical dystonia. $\boldsymbol{A}$, Box plots summarizing (left) and $\mathrm{MI}_{\text {gamma }}$ (right) over all STN-M1 recordings in PD versus dystonia. $p$ values are from the Wilcoxon rank sum test. $\boldsymbol{B}$

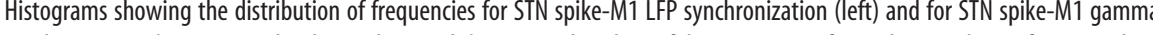
nization is provided in the results section. Data in $\boldsymbol{B}$ are only for recordings with an $\mathrm{MI}_{0}$ or $\mathrm{Ml}_{\text {gamma }}$ that reached statistical

Our findings support the evolving view that excessive synchronization between basal ganglia and cortex is a prominent feature of PD. We provide evidence that the parkinsonian state alters the statistical relationship between LFP phase and spike timing in global brain networks, not just in local basal ganglia or cortical circuits (Goldberg et al., 2004; Gatev and Wichmann, 2009; Li et al., 2012). Because many brain functions appear to depend on this mechanism for task performance (Fries, 2005), its disruption in a critical motor circuit could result in widespread impairment of motor functions. Our findings in humans are broadly consistent with several rodent studies of parkinsonism showing that dopamine denervation produces excessive 20-40 $\mathrm{Hz}$ synchronization of basal ganglia spiking with motor cortical LFP oscillations (Walters et al., 2007; Mallet et al., 2008; Galati et al., 2009; Brazhnik et al., 2012). The strong involvement of primary motor cortex in abnormal synchronization in humans has therapeutic implications, supporting the possibility of interrupting pathological synchronization at the level of the cortex (Drouot et al., 2004; Wu et al., 2007; Li et al., 2012), or of using a cortically based signal detector as a driver of basal ganglia deep brain stimulation in a closed loop paradigm (Rosin et al., 2011).

\section{STN spike-M1 gamma synchronization}

Our most novel finding is that STN spiking is also synchronized to M1 broadband gamma activity. Spike time averaged cortical gamma activity has a highly distinctive pattern, with waves of alternating high- and low-gamma amplitude, whose peak amplitude typically precedes the timing of STN spikes (median latency of $-48 \mathrm{~ms}$ ). These gamma waves have an oscillatory envelope in the theta, alpha, or beta ranges, demonstrating an interaction between the phase of low-frequency rhythms and the amplitude of broadband gamma. 

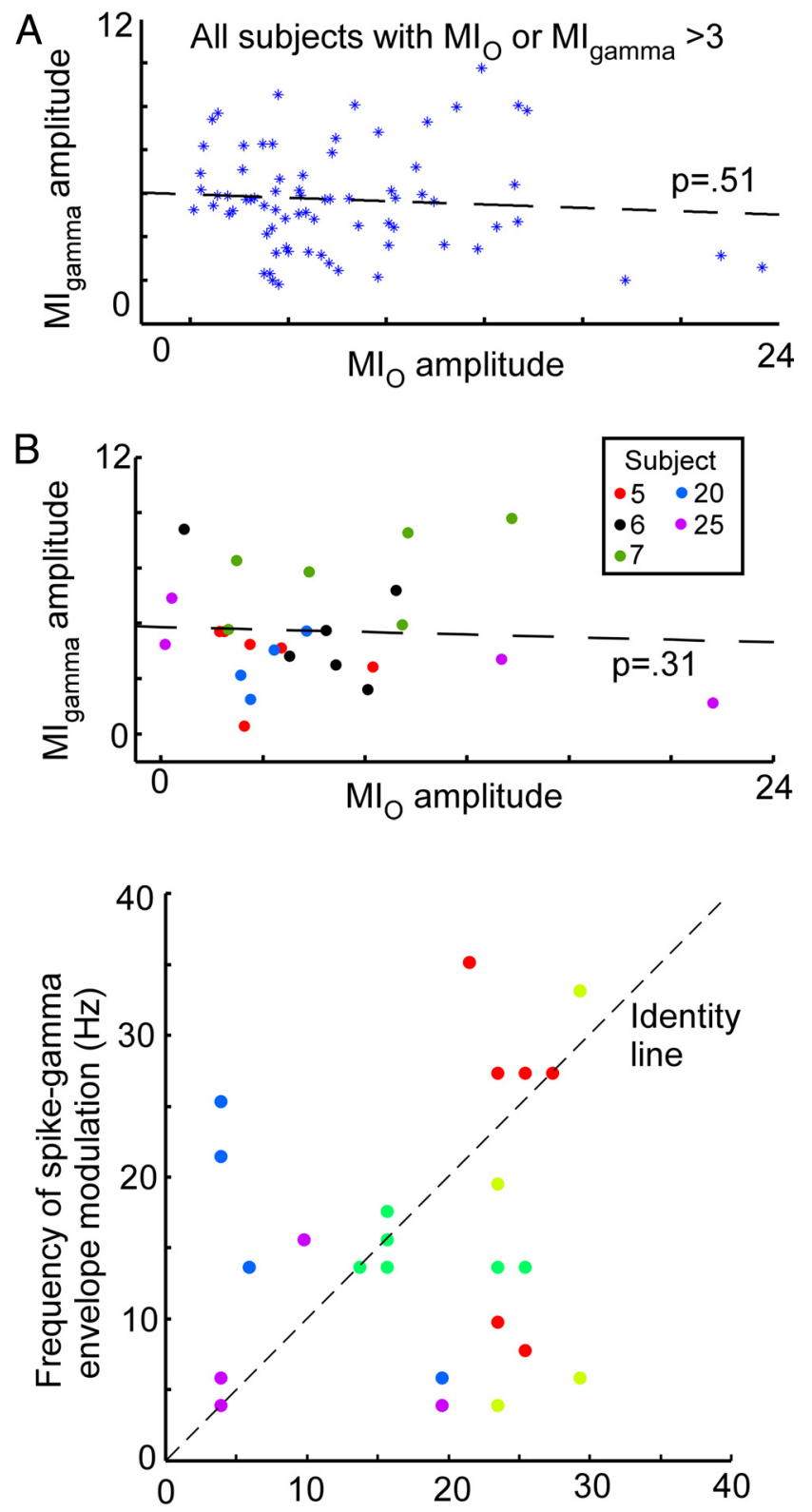

Frequency of spike-LFP modulation $(\mathrm{Hz})$

Figure 6. Relationship between STN spike-M1 LFP synchronization and STN-M1 gamma amplitude envelope synchronization in PD. $\boldsymbol{A}$, Lack of correlation between the magnitudes of $\mathrm{MI}_{0}$ and $\mathrm{MI}_{\text {gamma }}$ for all recordings with $\mathrm{MI}_{0}$ or $\mathrm{MI}_{\text {gamma }}$ (or both) $>3$. $\boldsymbol{B}$, The amplitudes (top plot) and frequencies (bottom plot) for the two types of synchronization ( $\mathrm{MI}_{0} \mathrm{vs}_{\mathrm{MI}}$ gamma ) are plotted for a subset of five PD subjects who each had at least 4 different units showing significant synchronization of at least one type. Data from each subject are color coded, to show that even within a given subject the oscillation frequencies for individual spike-LFP pairs were variable. In this subset, as in $\boldsymbol{A}$, there was no correlation between $\mathrm{MI}_{0}$ and $\mathrm{MI}_{\text {gamma }}$ with respect to either amplitude ( $p=0.31$ ) or preferred frequency $(p=0.32)$. In the bottom plot, the identity line is drawn to facilitate comparison between preferred frequencies for the different types of synchronization.

This finding has important implications for the role of crossfrequency interactions in movement disorders. Previous studies of STN LFPs have called attention to the possibility of phaseamplitude interactions as a biomarker of PD (Lopez-Azcarate et al., 2010; Ozkurt et al., 2011). These studies showed coupling between the beta rhythm and a narrow bandwidth, very highfrequency activity $(250-300 \mathrm{~Hz})$. Subsequently, we used M1 LFP recordings to demonstrate that PD patients have excessive coupling of the phase of the beta rhythm to broadband gamma amplitude (de Hemptinne et al., 2013). The present study directly links this abnormal cortical phase amplitude coupling to basal ganglia discharge, and indicates that epochs of M1 phase amplitude coupling statistically predict the timing of STN spiking. Further, we show a symptom and disease-specific pattern of spike-synchronized gamma activity: tremor severity is inversely related to the magnitude of spike-synchronized gamma activity in PD (at any frequency) (Fig. 4F; Table 3), and beta phase modulation of spike-synchronized gamma activity occurred uniquely in the parkinsonian state, not in craniocervical dystonia patients. In the cortex, we did not observe any narrow bandwidth, very high-frequency peaks of gamma activity in the $250-300 \mathrm{~Hz}$ range that were distinct from the broadband gamma range, as has been observed in the STN LFPs (Foffani et al., 2003; Lopez-Azcarate et al., 2010; Ozkurt et al., 2011).

In classical models of PD, STN hyperactivity is thought to result from abnormal synaptic transmission through intrinsic basal ganglia pathways involving the striatum, primarily the substantia nigra compacta $(\mathrm{SNc})$-striatum-globus pallidus externa (GPe)-STN pathway (Bergman et al., 1990). Our findings suggest an additional mechanism for STN hyperactivity in PD. Because cortical broadband gamma activity is thought to reflect underlying action potential firing (Manning et al., 2009), we propose that M1 drives STN hyperactivity via the corticosubthalamic pathway (Nambu et al., 2002). The organization of M1 spiking activity into phase-modulated waves of high and low amplitude is ideally suited to drive STN activity, because strong phasic inputs to STN at beta envelope frequencies would drive STN spiking more efficiently than an asynchronous increase in corticosubthalamic activity (Beurrier et al., 1999; Plenz and Kital, 1999; Bevan et al., 2002), and at a faster rate than phasic inputs at lower envelope frequencies. The latency between M1 population spiking and STN spiking is longer than can be explained by fast monosynaptic neurotransmission. This may relate to the membrane dynamics of STN cells, in which repetitive slow depolarization is especially effective for triggering spikes in "burst mode," thought to be characteristic of parkinsonism (Beurrier et al., 1999). A primary role for pathological activity in the corticosubthalamic pathway is also attractive in light of recent investigations in rodent models of $\mathrm{PD}$, showing that modulation of the corticosubthalamic pathway is important for amelioration of motor deficits (Gradinaru et al., 2009; Li et al., 2012). Further, modeling work indicates that network oscillations in the basal ganglia-thalamocortical circuit are enhanced in the setting of excessive corticosubthalamic driving of intrinsic basal ganglia pathways (Holgado et al., 2010).

\section{Limitations}

All recordings studied here were performed in a state of alert rest. We did not study patients during a movement task due to the extreme difficulty of holding stable unit activity for a long period of time during patient movement. We did not study patients in the on medication state, so it is not clear how dopamine replacement therapy would affect the observed STN-cortex interactions (Williams et al., 2002). Due to the smaller number of dystonia subjects implanted, the number of units in dystonia patients with sufficient spike numbers for comparison with PD was relatively small. Because our PD subjects had longstanding disease and had received chronic levodopa, our findings may represent compensatory changes rather than primary abnormalities, or may reflect long-term effects of chronic levodopa treatment that do not "wash out" in $12 \mathrm{~h}$ off of levodopa (Picconi et al., 2003). 


\section{Conclusions}

Using the novel approach of simultaneous recording of M1 LFPs and STN single units in awake humans undergoing DBS implantation surgery, we studied basal ganglia-cortex interactions on a fast time scale. In humans, we confirm the evidence from animal models that basal ganglia unit discharge in the parkinsonian state is strongly synchronized to cortical oscillatory activity. We further show that STN spiking is synchronized with cortical broadband gamma, and that the latter occurs in a phase-modulated pattern that begins before the occurrence of STN spikes. Abnormal cortical phase-amplitude coupling may be an important mediator of network oscillations in the basal gangliathalamocortical circuit.

\section{References}

Adamos DA, Kosmidis EK, Theophilidis G (2008) Performance evaluation of PCA-based spike sorting algorithms. Comput Methods Programs Biomed 91:232-244. CrossRef Medline

Bergman H, Wichmann T, DeLong MR (1990) Reversal of experimental parkinsonism by lesions of the subthalamic nucleus. Science 249:14361438. CrossRef Medline

Beurrier C, Congar P, Bioulac B, Hammond C (1999) Subthalamic nucleus neurons switch from single-spike activity to burst-firing mode. J Neurosci 19:599-609. Medline

Bevan MD, Magill PJ, Hallworth NE, Bolam JP, Wilson CJ (2002) Regulation of the timing and pattern of action potential generation in rat subthalamic neurons in vitro by GABA-A IPSPs. J Neurophysiol 87: 1348-1362. Medline

Brazhnik E, Cruz AV, Avila I, Wahba MI, Novikov N, Ilieva NM, McCoy AJ, Gerber C, Walters JR (2012) State-dependent spike and local field synchronization between motor cortex and substantia nigra in hemiparkinsonian rats. J Neurosci 32:7869-7880. CrossRef Medline

Costa RM, Lin SC, Sotnikova TD, Cyr M, Gainetdinov RR, Caron MG, Nicolelis MA (2006) Rapid alterations in corticostriatal ensemble coordination during acute dopamine-dependent motor dysfunction. Neuron 52:359-369. CrossRef Medline

Crone NE, Miglioretti DL, Gordon B, Sieracki JM, Wilson MT, Uematsu S, Lesser RP (1998) Functional mapping of human sensorimotor cortex with electrocorticographic spectral analysis: I. Alpha and beta eventrelated desynchronization. Brain 121:2271-2299. Medline

Crowell AL, Ryapolova-Webb ES, Ostrem JL, Galifianakis NB, Shimamoto S, Lim DA, Starr PA (2012) Oscillations in sensorimotor cortex in movement disorders: an electrocorticography study. Brain 135:615-630. CrossRef Medline

de Hemptinne C, Ryapolova-Webb ES, Air EL, Garcia P, Miller KJ, Ojemann JG, Ostrem JL, Galifianakis NB, Starr PA (2013) Exaggerated phaseamplitude coupling in the primary motor cortex in Parkinson's disease. Proc Natl Acad Sci U S A. Advance online publication. doi:10.1073/ pnas.1214546110. CrossRef Medline

Dostrovsky J, Bergman H (2004) Oscillatory activity in the basal ganglia: relationship to normal physiology and pathophysiology. Brain 127:721722. CrossRef Medline

Drouot X, Oshino S, Jarraya B, Besret L, Kishima H, Remy P, Dauguet J, Lefaucheur JP, Dollé F, Condé F, Bottlaender M, Peschanski M, Kéravel Y, Hantraye P, Palfi S (2004) Functional recovery in a primate model of Parkinson's disease following motor cortex stimulation. Neuron 44:769778. CrossRef Medline

Eusebio A, Pogosyan A, Wang S, Averbeck B, Gaynor LD, Cantiniaux S, Witjas T, Limousin P, Azulay JP, Brown P (2009) Resonance in subthalamo-cortical circuits in Parkinson's disease. Brain 132:21392150. CrossRef Medline

Fechner J, Ihmsen H, Hatterscheid D, Jeleazcov C, Schiessl C, Vornov JJ, Schwilden H, Schüttler J (2004) Comparative pharmacokinetics and pharmacodynamics of the new propofol prodrug GPI 15715 and propofol emulsion. Anesthesiology 101:626-639. CrossRef Medline

Foffani G, Priori A, Egidi M, Rampini P, Tamma F, Caputo E, Moxon KA, Cerutti S, Barbieri S (2003) 300-Hz subthalamic oscillations in Parkinson's disease. Brain 126:2153-2163. CrossRef Medline

Fogelson N, Williams D, Tijssen M, van Bruggen G, Speelman H, Brown P (2006) Different functional loops between cerebral cortex and the sub- thalmic area in Parkinson's disease. Cereb Cortex 16:64-75. CrossRef Medline

Fries P (2005) A mechanism for cognitive dynamics: neuronal communication through neuronal coherence. Trends Cogn Sci 9:474-480. CrossRef Medline

Galati S, Stanzione P, D’Angelo V, Fedele E, Marzetti F, Sancesario G, Procopio T, Stefani A (2009) The pharmacological blockade of medial forebrain bundle induces an acute pathological synchronization of the cortico-subthalamic nucleus-globus pallidus pathway. J Physiol 587:4405-4423. CrossRef Medline

Gatev P, Wichmann T (2009) Interactions between cortical rhythms and spiking activity of single basal ganglia neurons in the normal and parkinsonian state. Cereb Cortex 19:1330-1344. CrossRef Medline

Goldberg JA, Rokni U, Boraud T, Vaadia E, Bergman H (2004) Spike synchronization in the cortex/basal-ganglia networks of Parkinsonian primates reflects global dynamics of the local field potentials. J Neurosci 24:6003-6010. CrossRef Medline

Gradinaru V, Mogri M, Thompson KR, Henderson JM, Deisseroth K (2009) Optical deconstruction of parkinsonian neural circuitry. Science 324: 354-359. CrossRef Medline

Halliday DM, Rosenberg JR, Amjad AM, Breeze P, Conway BA, Farmer SF (1995) A framework for the analysis of mixed time series/point process data: theory and application to the study of physiological tremor, single motor unit discharges and electromyograms. Prog Biophys Mol Biol 64: 237-278. CrossRef Medline

Hammond C, Bergman H, Brown P (2007) Pathological synchronization in Parkinson's disease: networks, models and treatments. Trends Neurosci 30:357-364. CrossRef Medline

Hanley JA, Negassa A, Edwardes MD, Forrester JE (2003) Statistical analysis of correlated data using generalized estimating equations: an orientation. Am J Epidemiol 157:364-375. CrossRef Medline

Hanson TL, Fuller AM, Lebedev MA, Turner DA, Nicolelis MA (2012) Subcortical neuronal ensembles: an analysis of motor task association, tremor, oscillations, and synchrony in human patients. J Neurosci 32: 8620-8632. CrossRef Medline

Holgado AJ, Terry JR, Bogacz R (2010) Conditions for the generation of beta oscillations in the subthalamic nucleus-globus pallidus network. J Neurosci 30:12340-12352. CrossRef Medline

Hutchison WD, Allan RJ, Opitz H, Levy R, Dostrovsky JO, Lang AE, Lozano AM (1998) Neurophysiological identification of the subthalamic nucleus in surgery for Parkinson's disease. Ann Neurol 44:622-628. CrossRef Medline

Kühn AA, Trottenberg T, Kivi A, Kupsch A, Schneider GH, Brown P (2005) The relationship between local field potential and neuronal discharge in the subthalamic nucleus of patients with Parkinson's disease. Exp Neurol 194:212-220. CrossRef Medline

Lachaux JP, Axmacher N, Mormann F, Halgren E, Crone NE (2012) Highfrequency neural activity and human cognition: past, present and possible future of intracranial EEG research. Prog Neurobiol 98:279-301. CrossRef Medline

Lalo E, Thobois S, Sharott A, Polo G, Mertens P, Pogosyan A, Brown P (2008) Patterns of bidirectional communication between cortex and basal ganglia during movement in patients with Parkinson disease. J Neurosci 28: 3008-3016. CrossRef Medline

Leventhal DK, Gage GJ, Schmidt R, Pettibone JR, Case AC, Berke JD (2012) Basal ganglia beta oscillations accompany cue utilization. Neuron 73:523536. CrossRef Medline

Levy R, Hutchison WD, Lozano AM, Dostrovsky JO (2000) High-frequency synchronization of neuronal activity in the subthalamic nucleus of Parkinsonian patients with limb tremor. J Neurosci 20:7766-7775. Medline

Levy R, Hutchison WD, Lozano AM, Dostrovsky JO (2002a) Synchronized neuronal discharge in the basal ganglia of parkinsonian patients is limited to oscillatory activity. J Neurosci 22:2855-2861. Medline

Levy R, Ashby P, Hutchison WD, Lang AE, Lozano AM, Dostrovsky JO (2002b) Dependence of subthalamic nucleus oscillations on movement and dopamine in Parkinson's disease. Brain 125:1196-1209. CrossRef Medline

Li Q, Ke Y, Chan DC, Qian ZM, Yung KK, Ko H, Arbuthnott GW, Yung WH (2012) Therapeutic deep brain stimulation in parkinsonian rats directly influences motor cortex. Neuron 76:1030-1041. CrossRef Medline

Litvak V, Jha A, Eusebio A, Oostenveld R, Foltynie T, Limousin P, Zrinzo L, Hariz MI, Friston K, Brown P (2011) Resting oscillatory cortico- 
subthalamic connectivity in patients with Parkinson's disease. Brain 134: 359-374. CrossRef Medline

López-Azcarate J, Tainta M, Rodríguez-Oroz MC, Valencia M, González R, Guridi J, Iriarte J, Obeso JA, Artieda J, Alegre M (2010) Coupling between beta and high-frequency activity in the human subthalamic nucleus may be a pathophysiological mechanism in Parkinson's disease. J Neurosci 30:6667-6677. CrossRef Medline

Mallet N, Pogosyan A, Sharott A, Csicsvari J, Bolam JP, Brown P, Magill PJ (2008) Disrupted dopamine transmission and the emergence of exaggerated beta oscillations in subthalamic nucleus and cerebral cortex. J Neurosci 28:4795-4806. CrossRef Medline

Manning JR, Jacobs J, Fried I, Kahana MJ (2009) Broadband shifts in local field potential power spectra are correlated with single-neuron spiking in humans. J Neurosci 29:13613-13620. CrossRef Medline

Miller KJ, Leuthardt EC, Schalk G, Rao RP, Anderson NR, Moran DW, Miller JW, Ojemann JG (2007) Spectral changes in cortical surface potentials during motor movement. J Neurosci 27:2424-2432. CrossRef Medline

Moran A, Bergman H, Israel Z, Bar-Gad I (2008) Subthalamic nucleus functional organization revealed by parkinsonian neuronal oscillations and synchrony. Brain 131:3395-3409. CrossRef Medline

Murthy VN, Fetz EE (1996) Synchronization of neurons during local field potential oscillations in sensorimotor cortex of awake monkeys. J Neurophysiol 76:3968-3982. Medline

Nambu A, Tokuno H, Takada M (2002) Functional significance of the cortico-subthalamo-pallidal "hyperdirect" pathway. Neurosci Res 43: 111-117. CrossRef Medline

Nini A, Feingold A, Slovin H, Bergman H (1995) Neurons in the globus pallidus do not show correlated activity in the normal monkey, but phaselocked oscillations appear in the MPTP model of Parkinsonism. J Neurophysiol 74:1800-1805. Medline

Ossandón T, Jerbi K, Vidal JR, Bayle DJ, Henaff MA, Jung J, Minotti L, Bertrand O, Kahane P, Lachaux JP (2011) Transient suppression of broadband gamma power in the default-mode network is correlated with task complexity and subject performance. J Neurosci 31:14521-14530. CrossRef Medline

Ostrem JL, Racine CA, Glass GA, Grace JK, Volz MM, Heath SL, Starr PA (2011) Subthalamic nucleus deep brain stimulation in primary cervical dystonia. Neurology 76:870-878. CrossRef Medline

Özkurt TE, Butz M, Homburger M, Elben S, Vesper J, Wojtecki L, Schnitzler A (2011) High frequency oscillations in the subthalamic nucleus: a neurophysiological marker of the motor state in Parkinson's disease. Exp Neurol 229:324-331. CrossRef Medline

Pfurtscheller G, Stancák A Jr, Edlinger G (1997) On the existence of different types of central beta rhythms below $30 \mathrm{~Hz}$. Electroencephalogr Clin Neurophysiol 102:316-325. CrossRef Medline

Picconi B, Centonze D, Hakansson K, Bernardi G, Greengard P, Fisone G, Cenci MA, Calabresi P (2003) Loss of bidirectional striatal synaptic plasticity in L-DOPA-induced dyskinesia. Nat Neurosci 6:501-506. CrossRef Medline

Plenz D, Kital ST (1999) A basal ganglia pacemaker formed by the subthalamic nucleus and external globus pallidus. Nature 400:677-682. CrossRef Medline
Raz A, Bergman H, Eimerl D, Israel Z (2008) Propofol induced changes in the neuronal activity of subthalamic nucleus neurons. Mov Disord 23:S117.

Rivlin-Etzion M, Ritov Y, Heimer G, Bergman H, Bar-Gad I (2006) Local shuffling of spike trains boosts the accuracy of spike train spectral analysis. J Neurophysiol 95:3245-3256. CrossRef Medline

Rodriguez-Oroz MC, Rodriguez M, Guridi J, Mewes K, Chockkman V, Vitek J, DeLong MR, Obeso JA (2001) The subthalamic nucleus in Parkinson's disease: somatotopic organization and physiological characteristics. Brain 124:1777-1790. CrossRef Medline

Rosin B, Slovik M, Mitelman R, Rivlin-Etzion M, Haber SN, Israel Z, Vaadia E, Bergman H (2011) Closed-loop deep brain stimulation is superior in ameliorating parkinsonism. Neuron 72:370-384. CrossRef Medline

Schrock LE, Ostrem JL, Turner RS, Shimamoto SA, Starr PA (2009) The subthalamic nucleus in primary dystonia: single-unit discharge characteristics. J Neurophysiol 102:3740-3752. CrossRef Medline

Shahlaie K, Larson PS, Starr PA (2011) Intraoperative computed tomography for deep brain stimulation surgery: technique and accuracy assessment. Neurosurgery 68:114-124; discussion 124. CrossRef Medline

Starr PA, Christine C, Theodosopoulos PV, Mosely T, Byrd D, Lindsey N, Marks WJ (2002) Implantation of deep brain stimulator electrodes into the subthalamic nucleus: technical approach and magnetic resonance imaging-verified electrode locations. J Neurosurg 97:370-387. CrossRef Medline

Steigerwald F, Pötter M, Herzog J, Pinsker M, Kopper F, Mehdorn H, Deuschl G, Volkmann J (2008) Neuronal activity in the human subthalamic nucleus in the parkinsonian and nonparkinsonian state. J Neurophysiol 100: 2515-2524. CrossRef Medline

Walters JR, Hu D, Itoga CA, Parr-Brownlie LC, Bergstrom DA (2007) Phase relationships support a role for coordinated activity in the indirect pathway in organizing slow oscillations in basal ganglia output after loss of dopamine. Neuroscience 144:762-776. CrossRef Medline

Weinberger M, Mahant N, Hutchison WD, Lozano AM, Moro E, Hodaie M, Lang AE, Dostrovsky JO (2006) Beta oscillatory activity in the subthalamic nucleus and its relation to dopaminergic response in Parkinson's disease. J Neurophysiol 96:3248-3256. CrossRef Medline

Wenzelburger R, Zhang BR, Pohle S, Klebe S, Lorenz D, Herzog J, Wilms H, Deuschl G, Krack P (2002) Force overflow and levodopa-induced dyskinesias in Parkinson's disease. Brain 125:871-879. CrossRef Medline

Williams D, Tijssen M, Van Bruggen G, Bosch A, Insola A, Di Lazzaro V, Mazzone P, Oliviero A, Quartarone A, Speelman H, Brown P (2002) Dopamine-dependent changes in the functional connectivity between basal ganglia and cerebral cortex in humans. Brain 125:1558-1569. CrossRef Medline

Wu AK, McCairn KW, Zada G, Wu T, Turner RS (2007) Motor cortex stimulation: mild transient benefit in a primate model of Parkinson disease. J Neurosurg 106:695-700. CrossRef Medline

Yousry TA, Schmid UD, Alkadhi H, Schmidt D, Peraud A, Buettner A, Winkler P (1997) Localization of the motor hand area to a knob on the precentral gyrus: a new landmark. Brain 120:141-157. CrossRef Medline 